\title{
Análisis de los principales elementos de la sentencia de la Corte Internacional de Justicia en el caso de la controversia marítima (Perú c. Chile) a la luz de las posiciones de las partes Analysis of the main elements of the International Court of Justice Judgment in the maritime dispute (Peru v. Chile) in the light of the parties positions
}

\section{PABLO MOSCOSO DE LA CUBA*}

Dicho caso presentó un nuevo y peculiar escenario fáctico respecto a las diametralmente opuestas tesis defendidas por las Partes respecto a su límite marítimo en el Océano Pacífico. Ciertamente, las Partes presentaron opuestos - y fundamentalmente diferentes - puntos de vista sobre cómo debía proceder la Corte respecto a la asignación de sus respectivas áreas marítimas.

Peter Tomka ${ }^{1}$

Resumen: El 27 de enero de 2014, la Corte Internacional de Justicia (CIJ), órgano judicial principal de la organización de las Naciones Unidas, dio su sentencia en el caso de la controversia marítima (Perú c. Chile), el cual el Perú presentó ante ella en enero de 2008. Durante el proceso ante la Corte, las partes presentaron posiciones fundamentalmente distintas sobre la existencia de un límite marítimo entre ellas y sobre cómo la Corte debía proceder para resolver este caso. Para llegar a su fallo, la Corte debió evaluar esos múltiples argumentos legales planteados por ambos Estados a lo largo de años. En particular, varios de los argumentos legales planteados por el Perú fueron aceptados por la Corte y acogidos en el fallo, desde la interpretación que dio a las proclamaciones de Perú y Chile de 1947, pasando por los argumentos que planteó el Perú sobre la Declaración de Santiago de 1952 (que había sido el núcleo del caso argumentado por Chile, el cual fue descartado por la Corte), hasta el argumento peruano en el sentido de que el Convenio sobre Zona Especial Fronteriza Marítima de 1954 no creó una zona de tolerancia que se extienda por doscientas millas marinas. Sin embargo, la Corte consideró que en ese tratado de 1954 las partes reconocieron la existencia de un acuerdo tácito, figura que no argumentaron las partes ante la Corte, pero que tiene su fundamentación legal en jurisprudencia previa de la CIJ. La Corte luego tuvo que determinar la extensión de ese acuerdo legal tácito, labor sumamente

* Máster de estudios avanzados en Derecho Internacional Público por la Universidad de Leiden, Países Bajos, y abogado por la Pontificia Universidad Católica del Perú (PUCP). Docente del Departamento Académico de Derecho de la PUCP. Fue asesor legal de la delegación oficial del Perú durante las audiencias orales del caso de la controversia marítima entre el Perú y Chile. El presente artículo ha sido escrito a título estrictamente personal y no compromete ni refleja la posición de entidad pública o privada alguna. El autor agradece a Marisol Agüero Colunga por sugerir su nombre para la elaboración de este texto pero el contenido es responsabilidad entera del autor. Correo electrónico: pmoscoso@pucp.pe

1 «Discurso de S.E. Peter Tomka, presidente de la Corte Internacional de Justicia, en la Sexagésima Sexta Sesión de la Comisión de Derecho Internacional», 22 de julio de 2014, p. 4 (http://legal.un.org/ ilc/sessions/66/Statement\%28Pres.Tomka\%29.pdf). Todas las traducciones son del autor. 
difícil ya que las partes no habían contemplado la existencia de esa figura ni argumentado hasta dónde se habría extendido la misma. Luego de establecer que el acuerdo legal tácito se extendía por ochenta millas marinas a lo largo de un paralelo de latitud, la Corte procedió a establecer un límite marítimo siguiendo exactamente las normas y principios sobre delimitación marítima planteados por el Perú, los cuales aplicados al caso determinan el establecimiento de una línea equidistante. Con relación al punto de inicio del límite marítimo, la Corte no empleó el punto planteado por el Perú pero, correctamente, dejó en claro que el punto de inicio del límite marítimo y el punto de inicio del límite terrestre no tienen necesariamente que coincidir. Finalmente, la manera como la Corte estableció el límite marítimo reconoce sin lugar a duda que el área antes llamada «triángulo exterior» corresponde exclusivamente al Perú, como ese Estado argumentó y Chile se opuso repetidas veces a lo largo de los años. En resumen, se trata de una decisión ajustada al derecho internacional y tomada sobre la base de la evidencia a disposición de la Corte, en la que esta emplea y confirma diversos de los argumentos legales planteados por el Perú durante el proceso, a pesar de todo lo que Chile argumentó contrariamente.

Palabras clave: Corte Internacional de Justicia - delimitación marítima - límite marítimo - frontera marítima - decreto supremo 781 de 1947 - Declaración de Santiago de 1952 -Convenio sobre Zona Especial Fronteriza Marítima de 1954 Punto Concordia - Hito Número Uno - punto de inicio del límite marítimo

Abstract: On January 27, 2014 the International Court of Justice, principal judicial organ of the United Nations ruled in the case of the maritime dispute (Peru v. Chile), being Peru the one that brought forth the case in January 2008. During the proceedings in Court, the parties presented fundamentally different positions on the existence of a maritime boundary between them and how the Court should proceed solving the dispute. The Court should have considered the multiple legal reasonings presented by the States parties over the years to arrive to its ruling. Particularly, some of the legal reasonings presented by Peru were accepted by the Court and considered in the ruling, beginning from the interpretation given to the proclamations of Peru and Chile in 1947, going through the reasonings Peru presented about the 1952 Santiago Declaration (It was the main topic presented by Chile, which was discarded by the Court) until the reasoning presented by Peru saying that the 1954 Special Maritime Frontier Zone Agreement didn't create a zone of tolerance that extends to 200 nautical miles. However, the Court considered that in the 1954 agreement the parties accepted the existence of a tacit agreement, but this existence was not presented by them in the Court even though it has a legal support in the jurisprudence of the International Court of Justice. Then, the Court had to determine the extent of the tacit agreement, a very difficult duty because the parties hadn't considered the existence of that situation and its extension. After establishing the implied legal agreement was for 80 nautical miles along a parallel of latitude, the Court proceeded to establish a maritime boundary applying thoroughly the rules and principles of maritime delimitation presented by Peru, which applied to the case determine the presence of an equidistant line. In relation to the starting-point of the maritime boundary, the Court didn't use the point presented by Peru but, in a correct way, made it clear that the starting-point 
of the maritime boundary and the starting-point of the land boundary don't have to match necessarily. Finally, the way how the Court established the maritime boundary recognizes, with no doubt, that the area previously named "outer triangle" belongs to Peru, as this country claimed and as Chile opposed repeatedly over the years. In summary, it is a decision based on International Law and adopted under the evidence presented in Court. The Court applied and confirmed various legal arguments presented by Peru during the process, in spite of the opposing position of Chile.

Key words: International Court of Justice - maritime delimitation - maritime boundary - maritime border - Supreme Decree 781 of 1947 - 1952 Santiago Declaration - 1954 Special Maritime Frontier Zone Agreement - Punto Concordia - point named Concordia - Boundary Marker number 1 - starting point of the maritime boundary

CONTENIDO: I. INTRODUCCIÓN.- II. ASPECTOS GENERALES DEL PROCESO Y DE LA COMPETENCIA DE LA CORTE.- III. EL PUNTO DE PARTIDA DE LAS POSICIONES DE LAS PARTES EN EL CASO.- III.1 DEL PERÚ.- III.2. DE CHILE.IV. LA DISCUSIÓN SOBRE LA EXISTENCIA DEL LÍMITE MARÍTIMO.- IV.1 LAS PROCLAMACIONES DE 1947.- IV.2. LA DECLARACIÓN DE SANTIAGO DE 1952.- IV.3. EL CONVENIO SOBRE ZONA ESPECIAL FRONTERIZA MARÍTIMA DE 1954.- IV.4. EL ACUERDO TÁCITO.- IV.4.1. RECONOCIMIENTO DE UN ACUERDO TÁCITO.- IV.4.2. EL ACUERDO TÁCITO PARA LA CORTE INTERNACIONAL DE JUSTICIA.- IV.4.3. EXTENSIÓN DEL LÍMITE MARÍTIMO DERIVADO DEL ACUERDO TÁCITO.- V. EL PUNTO DE INICIO DEL LÍMITE MARÍTIMO.- VI. EL TRAZADO DEL LÍMITE MARÍTIMO MÁS ALLÁ DEL PUNTO DONDE TERMINA EL PARALELO.VII.LOSDERECHOSDELPERÚENELÁREAUBICADADENTRODELASDOSCIENTAS MILLAS MARINAS DE SUS LÍNEAS DE BASE PERO MÁS ALLÁ DE LAS DOSCIENTAS MILLAS MARINAS DE LAS LÍNEAS DE BASE DE CHILE.- VIII. EL PÁRRAFO 178 Y LA INVOCACIÓN DEL PERÚ A LA COSTUMBRE INTERNACIONAL EN EL CASO.IX. EL ENCARGO A LAS PARTES PARA QUE DETERMINEN LAS COORDENADAS DEL LÍMITE MARÍTIMO.- X. CONCLUSIÓN: ¿UN FALLO «SALOMÓNICO»?

\section{INTRODUCCIÓN}

Este artículo tiene como objeto analizar los elementos centrales de la decisión de la Corte Internacional de Justicia (CIJ), órgano judicial principal de la Organización de las Naciones Unidas $(\mathrm{ONU})^{2}$, en el caso que la propia Corte denominó «controversia marítima (Perú c. Chile)» 3 .

2 El artículo 92 de la Carta de la ONU, tratado constitutivo de dicha organización internacional, establece que «[l]a Corte Internacional de Justicia será el órgano judicial principal de las Naciones Unidas; funcionará de conformidad con el Estatuto anexo, que está basado en el de la Corte Permanente de Justicia Internacional, y que forma parte integrante de esta Carta». El Estatuto de la ClJ cuenta, entonces, con naturaleza de tratado internacional. Por su parte, el Estatuto (artículo 30.1) faculta a la Corte a aprobar su Reglamento.

3 En inglés maritime dispute y en francés différend maritime (los dos idiomas oficiales de la Corte). Los textos en castellano del Estatuto y del Reglamento de la CIJ, así como la propia Carta de la ONU

ANÁLISIS DE LOS PRINCIPALES

ELEMENTOS DE

LA SENTENCIA

DE LA CORTE

INTERNACIONAL

DE JUSTICIA EN

EL CASO DE LA

CONTROVERSIA

MARÍTIMA (PERÚ C.

CHILE) A LA LUZ DE

LAS POSICIONES

DE LAS PARTES

ANALYSIS OF

THE MAIN

ELEMENTS OF THE

INTERNATIONAL

COURT OF JUSTICE

JUDGMENT IN THE

MARITIME DISPUTE

(PERU V. CHILE) IN

THE LIGHT OF THE

PARTIES POSITIONS 
Este no es entonces, ni podría ser, un análisis completo o definitivo de la sentencia o fallo ${ }^{4}$ de la CIJ de 27 de enero de 2014. Limitaciones de tiempo y espacio, así como la complejidad del propio fallo y del caso entero, hacen que esa labor resulte imposible en un texto como este.

Para este análisis recurriremos frecuentemente a los argumentos planteados por las partes ante la Corte a lo largo del proceso ya que, como se observará más adelante, esos argumentos fueron en muchos casos decisivos para que la Corte decida sobre las pretensiones de las partes. Ello a pesar de que en diversos aspectos el texto de la sentencia no explica completamente las posiciones de las partes.

En efecto, las partes presentaron sus argumentos a lo largo de un proceso que duró varios años, el cual se inició el 16 de enero de 2008, cuando el Perú presentó su solicitud a la Corte ${ }^{5}$ y solo concluyó con el fallo de enero de 2014. Así, el material que contiene las argumentaciones de las partes es muy vasto. Los argumentos escritos de estas están contenidos en 18 volúmenes que consisten en 4 volúmenes propiamente de argumentación escrita (haciendo un total de 1317 páginas), 10 volúmenes que contienen un total de 715 anexos y 4 volúmenes con 200 gráficos y mapas. Adicionalmente, las presentaciones de las partes durante las audiencias orales de diciembre de 2012 están registradas en 638 páginas de trascripciones ${ }^{6}$.

Así, los 198 párrafos del fallo, incluso si se añaden las 10 opiniones separadas, opiniones disidentes y declaraciones de los jueces que lo acompañan ${ }^{7}$, solo pueden contener una explicación muy resumida, y en ciertos casos limitada, de algunos de los argumentos invocados por las partes. Inevitablemente, en ciertos aspectos, el resumen que hace la Corte de las posiciones de las partes se encuentra muy simplificado y

(artículos 2.3, 33, etcétera) emplean exclusivamente el término «controversia» como equivalente de dispute o différend. Por ello, preferimos referirnos al caso como "controversia» marítima, en lugar de "disputa» o «diferendo» marítimo.

4 El texto en castellano del Estatuto de la Corte emplea, alternativamente, los términos "sentencia" (artículos 27 y 39) o "fallo» (artículos 41 y 56, entre otros) para referirse a las decisiones que esta emite para decidir sobre el fondo de un caso.

5 El artículo 40.1 del Estatuto señala que una de las formas de iniciar un proceso ante la Corte es «mediante solicitud escrita dirigida al Secretario». La solicitud es lo que comúnmente se conoce como la "demanda» de un Estado ante la ClJ, aunque el Estatuto y Reglamento no emplean el término demanda para referirse a ese documento inicial.

6 Los 4 volúmenes con argumentos escritos y las transcripciones de las audiencias orales se encuentran en inglés y francés en la página web de la Corte, los dos idiomas oficiales de la CIJ (artículo 39.1 del Estatuto). Ver http://www.icj-cij.org/docket/index.php?p1=3\&p2=3\&code=pch\&cas $\mathrm{e}=137 \& \mathrm{k}=88 \& \mathrm{p} 3=0$. Los demás volúmenes no han sido publicados por la Corte. Por otro lado, no existen traducciones oficiales al español elaboradas por la CIJ de estos textos. Si bien las audiencias orales de diciembre de 2012 y la lectura de la sentencia en enero de 2014 fueron transmitidas e interpretadas en directo al español, la primera vez que ello ha ocurrido en la historia de décadas de la Corte, dichas interpretaciones fueron solo referenciales.

7 Los jueces pueden redactar opiniones separadas si han votado a favor de la decisión de la Corte pero difieren de la argumentación contenida en el fallo; opiniones disidentes, si votaron en contra de la decisión y, por tanto, el fallo no expresa en todo o en parte su punto de vista; así como declaraciones si desean dejar constancia de su acuerdo o desacuerdo con la decisión sin emitir una de las más formales opiniones anteriores (artículos 57 del Estatuto y 95.2 del Reglamento). 
puede inducir a error a quien solo se base en ese texto para calificar o explicar qué argumentó cada parte en determinadas materias. Lo aquí afirmado se ira haciendo más claro al lector conforme se desarrolle este artículo.

Por otro lado, diversas autoridades, analistas y políticos chilenos, así como algunos peruanos de manera limitada, han venido expresando pública o privadamente que la Corte dio la razón legal en el caso a Chile pero que, por razones extralegales, el Perú obtuvo un resultado positivo o muy positivo. Quienes afirman ello señalan que el argumento central de Chile era que existía un acuerdo entre los dos Estados y que la Corte determinó precisamente ello mediante la figura del acuerdo tácito. Por otro lado, afirman que la Corte decidió sobre la base de la equidad, a secas, e incluso al margen del derecho, y eso fue lo que favoreció finalmente al Perú ${ }^{8}$. Ambas visiones son incorrectas y serán abordadas y refutadas a lo largo de este artículo.

Quienes afirman que la Corte otorgó la razón legal a Chile se olvidan de que, a lo largo de todo el procedimiento, en innumerables ocasiones y sin ofrecer argumentos alternativos, Chile indicó que el acuerdo que estableció el límite marítimo entre el Perú y Chile fue la Declaración de Santiago de 1952. Y de la Declaración, en concreto, su punto IV. Para Chile, entonces, el límite marítimo fue acordado mediante un tratado internacional expreso y escrito. Ese límite, para Chile, había sido completa y definitivamente pactado, se extendía por doscientas millas marinas y, entonces, la Corte no tenía nada que delimitar en el caso. Como será demostrado, ese fue el verdadero núcleo de la posición legal de Chile en relación con la delimitación en el área de superposición y a la que el Perú tuvo que enfrentarse en el caso. Como se desarrollará, todos esos argumentos presentados por Chile fueron rechazados por la Corte y fueron rechazados porque el Perú los discutió durante el proceso, no los aceptó ni se allanó respecto a ellos, brindando más bien los elementos que la Corte empleó para rechazarlos.

En cambio, como se verá, la Corte decidió que las partes habían llegado previamente a un acuerdo (tácito) sobre su límite marítimo pero solo

8 Para un profesor de la Universidad de Chile la «sentencia de 27 de enero no aplica objetivamente el Derecho Internacional. No cumple, en consecuencia, con el fin que le fija el artículo 38 del Estatuto de la Corte. Lo abandona y, en su subjetividad, hace una amalgama extrajurídica" (ARNELLO ROMO, Mario. «La sentencia de la Corte Internacional de Justicia sobre el límite marítimo Perú c. Chile confirma la pérdida de juridicidad que prevalece en la justicia internacional. Análisis de una sentencia que en parte falló en derecho, que se tornó arbitraria, y que, al ser predecible, obliga a una reflexión crítica sobre estrategias y defensas». Revista Tribunal Internacional. 3 (2014), p. 67). Para otra autora chilena, en «definitiva, las consideraciones sobre las que se basa el fallo se acercan más a la búsqueda de una solución sobre la base de la equidad que a la búsqueda de la existencia de un acuerdo entre las Partes. [...] El problema fundamental, aquí, es la voluntad implícita de la Corte de invertir el orden jerárquico de las normas y de recurrir, de manera global, a la equidad para inspirar la decisión». AGUAYO ARMIJO, Francisca. «Reflexiones sobre el derecho internacional y la delimitación marítima. Comentario del fallo de la Corte Internacional de Justicia en el caso Perú c. Chile». Revista Tribunal Internacional. 3, 5 (2014), p. 102. 
de manera parcial y, al decidir ello, no empleó ningún argumento legal planteado por Chile. No fue ese el pedido planteado por el Perú, es cierto, pero la decisión de la Corte sobre el acuerdo tácito fue tomada por ella a pesar de los argumentos legales de Chile y no gracias a ellos. En cambio, el Perú brindó los elementos para que la Corte limite, exitosamente, la extensión del límite del paralelo geográfico a menos de doscientas millas marinas.

También es evidente que ahí donde la Corte tuvo que delimitar, aplicó todos los argumentos que el Perú planteó. El mito de que la Corte dio la razón legal a Chile, entonces, simplifica demasiado las posiciones de las partes en el caso, así como deja de lado el segundo pedido del Perú a la Corte (sobre el antes llamado «triángulo exterior»). Por todo lo anterior, a lo largo del trabajo se irá demostrando el valor decisivo que dio la Corte a diversos argumentos legales planteados por el Perú.

El trabajo se dividirá de la siguiente manera: luego de esta introducción, el punto II del artículo desarrollará algunos aspectos generales del proceso y de la competencia de la Corte. Seguidamente, se analizarán consecutivamente los siguientes puntos: el punto de partida de la posición de cada parte en el caso (punto III), la discusión sobre la existencia del límite marítimo y el acuerdo tácito (punto IV), la delimitación efectuada por la Corte más allá del paralelo que alcanza las ochenta millas marinas (punto V). A ello le seguirá el punto de inicio del límite marítimo (punto VI), los derechos del Perú en el área antes conocida como «triángulo exterior» (punto VII), el párrafo 178 y la invocación del Perú a la costumbre internacional (punto VIII) y el encargo a las partes para que determinen las coordenadas del límite marítimo (punto IX). Como conclusión, se evaluará si la Corte emitió un fallo «salomónico» (punto X).

\section{ASPECTOS GENERALES DELPROCESO Y DE LA COMPETENCIA DE LA CORTE}

La sentencia del 27 de enero de 2014 concluyó el proceso que el Perú inició ante la Corte en su solicitud del 16 de enero de 2008. Durante el periodo de poco más de seis años que transcurrió entre la presentación de la solicitud y la emisión de la sentencia tuvieron lugar las fases escrita y oral del procedimiento que establece el artículo 43.1 del Estatuto de la Corte (hasta diciembre de 2012) y, luego de ello, la Corte tomó poco más de treces meses en deliberar, así como en elaborar y pronunciar su fallo.

La fase escrita del procedimiento ante la CIJ consistió en la presentación de una Memoria por parte del Perú (MP) el 20 de marzo de 2009, una Contramemoria por parte de Chile (CMC) el 9 de marzo de 2010, 
seguidas de la Réplica del Perú (RP) el 9 de noviembre de 2010 y la Dúplica de Chile (DC) el 11 de julio de 2011. La fase oral consistió en la realización de audiencias públicas en las que la Corte escuchó a agentes y abogados de las partes. Tuvieron lugar entre el 3 y el 14 de diciembre de 2012 en el Auditorio de la Academia de Derecho Internacional de La Haya, en dicha ciudad holandesa, en tanto el cercano Gran Salón de Justicia del Palacio de la Paz, donde la Corte normalmente se reúne, se encontraba en remodelación. Los argumentos escritos y orales de las partes también son llamados alegatos escritos y orales en el Estatuto y Reglamento de la Corte 9 .

A partir de la solicitud de 2008 y, posteriormente, en cada uno de sus alegatos escritos y al final de sus alegatos orales ante la Corte, el Perú hizo los mismos dos pedidos a la CIJ. En concreto, solicitó que esta determine que:

(1) La delimitación entre las respectivas zonas marítimas entre la República del Perú y la República de Chile es una línea que se inicia en el «Punto Concordia» (definido como la intersección con la línea de bajamar de un arco de 10 kilómetros de radio, el cual tiene su centro en el primer puente sobre el Río Lluta del ferrocarril Arica-La Paz) y que es equidistante de las líneas de base de ambas Partes, hasta un punto situado a una distancia de 200 millas marinas de dichas líneas de base, y

(2) Más allá del punto en que el límite marítimo común termina, el Perú tiene el derecho a ejercer derechos soberanos exclusivos sobre un área marítima ubicada hasta una distancia de 200 millas marinas de sus líneas de base ${ }^{10}$.

Por su parte, Chile cuestionó ambos pedidos y, como regla general, se opuso a todos los argumentos legales planteados por el Perú. Sus conclusiones finales fueron que la Corte decida que:

(i) los respectivos derechos sobre zonas marítimas de Chile y Perú han sido completamente delimitados mediante acuerdo;

(ii) aquellos derechos sobre zonas marítimas están delimitados por un límite que sigue el paralelo de latitud que pasa a través del hito más cercano al mar del límite terrestre entre Chile y Perú, conocido como Hito No. 1, el cual tiene una latitud de $18^{\circ} 21^{\prime} 00^{\prime \prime}$ S en el Datum WGS84; y

9 Véanse, por ejemplo, los artículos 39.2 y 48 del Estatuto y, del Reglamento, los artículos 26.1.d, 44.1, $45,58.1$, etcétera.

10 Discurso del agente del Perú ante la ClJ, embajador Allan Wagner, en su presentación final el 11 de diciembre de 2012. Transcripción (compte rendu) CR 2012/34, p. 44 (http://www.icj-cij.org/ docket/files/137/17220.pdf). Los pedidos de una parte, expresados por su agente al final de las presentaciones de su Estado en las audiencias orales son llamadas, en la versión en español del Reglamento de la Corte, "conclusiones finales", término que en realidad no equivale a los empleados en inglés (final submissions) y francés (thèses), los dos idiomas oficiales de la Corte.

ANÁLISIS DE LOS PRINCIPALES

ELEMENTOS DE

LA SENTENCIA

DE LA CORTE

INTERNACIONAL

DE JUSTICIA EN

EL CASO DE LA

CONTROVERSIA

MARÍTIMA (PERÚ C.

CHILE) A LA LUZ DE

LAS POSICIONES

DE LAS PARTES

ANALYSIS OF

THE MAIN

ELEMENTS OF THE

INTERNATIONAL

COURT OF JUSTICE

JUDGMENT IN THE

MARITIME DISPUTE

(PERU V. CHILE) IN

THE LIGHT OF THE

PARTIES POSITIONS 
(iii) Perú no tiene ningún derecho a ninguna zona marítima que se extienda hacia el sur de dicho paralelo ${ }^{11}$.

La competencia de la Corte para resolver esta controversia marítima se derivó del Tratado Americano de Soluciones Pacíficas de 1948, o «Pacto de Bogotá», del cual tanto el Perú como Chile eran partes sin reservas al momento de la emisión del fallo (y continúan siéndolo). En concreto, el artículo XXXI de dicho tratado confiere jurisdicción a la Corte para resolver «todas las controversias de orden jurídico» que surjan entre las partes «y que versen sobre: a) La interpretación de un Tratado; b) Cualquier cuestión de Derecho Internacional [...]».

Por su parte, el artículo VI del Pacto de Bogotá señala que no se aplicarán los procedimientos de solución pacífica de controversias contemplados en el Pacto, incluyendo el recurso a la CIJ, «a los asuntos ya resueltos por arreglo de las partes, o por laudo arbitral, o por sentencia de un tribunal internacional, o que se hallen regidos por acuerdos o tratados en vigencia en la fecha de la celebración del presente Pacto».

Es de notar que, a pesar de que Chile afirmó a lo largo del proceso que la totalidad del límite marítimo había sido establecido previamente por las partes, en otras palabras, que el caso de delimitación marítima planteado por el Perú ya había sido resuelto por arreglo de las partes en el sentido del artículo VI del Pacto de Bogotá, no presentó una excepción preliminar para que la Corte se declare incompetente para resolver la controversia $^{12}$.

Un factor que pudo haber influido en esa decisión de Chile probablemente fue que el 13 de diciembre de 2007, el mes anterior a la presentación de la solicitud del Perú, la CIJ resolvió la solicitud de excepciones preliminares de Colombia en el caso terrestre y marítimo entre ese Estado y Nicaragua. En esa ocasión, Colombia invocó precisamente el artículo VI del Pacto de Bogotá para intentar que la Corte no resuelva el asunto de fondo, pero la CIJ, luego de analizar la excepción en una decisión de 142 párrafos, solo aceptó la excepción preliminar parcialmente. Para la CIJ, Nicaragua y Colombia ya habían resuelto la cuestión de la soberanía sobre las tres principales islas del archipiélago de San Andrés, en el mar Caribe, pero no sobre otras numerosas formaciones terrestres menores

11 Discurso del agente de Chile ante la ClJ, embajador Alberto Van Klaveren, en su presentación final el 14 de diciembre de 2012. Transcripción CR 2012/36, p. 47 (http://www.icj-cij.org/docket/ files/137/17234.pdf). Las cursivas son nuestras.

12 Según el artículo 79.1 del Reglamento de la Corte, «[c]ualquier excepción a la competencia de la Corte o a la admisibilidad de la solicitud, o cualquier otra excepción sobre la cual el demandado pide que la Corte se pronuncie antes de continuar el procedimiento sobre el fondo, deberá ser presentada por escrito lo antes posible, y a más tardar en el plazo de tres meses a partir de la presentación de la memoria». 
en la zona. Tampoco contaban con un acuerdo de límites marítimos, como Colombia alegó ${ }^{13}$. El caso sobre el fondo, entonces, continuó.

Dado que Chile estaba tan convencido de que la Declaración de Santiago de 1952 estableció completamente el límite marítimo entre el Perú y Chile, como empezaría a argumentar en su Contramemoria, resulta llamativo que haya optado por no presentar la referida excepción preliminar. Lo curioso del asunto radica en que, luego de no presentarla, toda su argumentación ante la Corte apuntó a que la Corte no tenía nada que resolver en materia de delimitación marítima entre el Perú y Chile pues el asunto ya había sido resuelto por arreglo de las partes.

\section{EL PUNTO DE PARTIDA DE LAS POSICIONES DE LAS PARTES EN EL CASO}

\section{III.1. Del Perú}

El Perú, como Estado demandante, presentó a la Corte los primeros documentos que sustentaban su posición legal, la solicitud de enero de 2008 y la Memoria de marzo de 2009. No fue hasta la Contramemoria de marzo de 2010 que se supo cuál era la posición legal concreta, específica, de Chile en el caso.

En efecto, antes de que se inicie el proceso, Chile había expresado que un límite marítimo existía entre los dos Estados pero no había sido preciso respecto a dónde o cómo se había acordado dicho límite. De hecho, la posición de Chile antes del proceso fue cambiando con el tiempo. Así, luego de que el Perú por primera vez planteara a Chile la necesidad de negociar bilateralmente un límite marítimo, a través de la misión del embajador Bákula en 1986 y el Memorándum que entregó al Canciller chileno de la época, la respuesta de Chile fue que, simplemente, se harían estudios sobre el particular ${ }^{14}$. No afirmó que existiese un límite marítimo o que hubiese sido acordado en la Declaración de Santiago, como lo hizo a lo largo del proceso.

Por su parte, luego de que el Perú propuso nuevamente, en julio de 2004, que se realicen negociaciones bilaterales sobre ese tema ${ }^{15}$, la respuesta de Chile fue que «no resulta procedente referirse a negociaciones sobre convenios vigentes, que han establecido el límite marítimo» ${ }^{16}$. Nótese

13 "Controversia territorial y marítima (Nicaragua c. Colombia). Excepciones preliminares, sentencia». I.C.J. Reports 2007, p. 832.

14 MP, párrafo 17.

15 lbídem, párrafo 23.

16 Nota de la ministra de Relaciones Exteriores de Chile al ministro de Relaciones Exteriores del Perú de 10 de septiembre de 2004 (http://www.congreso.gob.pe/comisiones/2008/seguimiento-demandaperuana/ documentos/NotaMinistroRREEChile-10-09-2004.pdf). Ver también MP, párrafo 24.

ANÁLISIS DE LOS PRINCIPALES

ELEMENTOS DE

LA SENTENCIA

DE LA CORTE

INTERNACIONAL

DE JUSTICIA EN

EL CASO DE LA

CONTROVERSIA

MARÍTIMA (PERÚ C.

CHILE) A LA LUZ DE

LAS POSICIONES

DE LAS PARTES

ANALYSIS OF

THE MAIN

ELEMENTS OF THE

INTERNATIONAL

COURT OF JUSTICE

JUDGMENT IN THE

MARITIME DISPUTE

(PERU V. CHILE) IN

THE LIGHT OF THE

PARTIES POSITIONS 
que en ese momento para Chile existían «convenios», en plural, que establecieron el límite.

Es así que cuando el Perú preparó su solicitud y su Memoria lo hizo bajo una situación especial. Se presentaba ante la Corte como demandante pero para afirmar que algo no existía (el límite marítimo) y lo hacía sin saber cómo fundamentaría exactamente Chile la existencia del límite marítimo. Usualmente, el Estado demandante es el que se presenta ante la Corte afirmando que algo existe (una obligación jurídica internacional, un límite internacional violado por la otra partes, etcétera) y el Estado demandado, por lo general, asume la posición de que la obligación no existe, o que no tiene el alcance que le atribuye la otra parte, o que no la ha violado.

Sin embargo, el Perú sí conocía, como afirmó en su Memoria, que «[n]i la Declaración de Santiago ni el Convenio sobre Zona Especial Fronteriza Marítima de 1954 establecieron un límite marítimo entre el Perú y Chile» ${ }^{17}$. De hecho, como se desprende de la misma Memoria, sabía que Chile no podría producir documento expreso alguno en el que se haya pactado el límite marítimo.

La real inexistencia de un límite marítimo acordado en un instrumento internacional determinable, como la Corte confirmó en su fallo (se verá más adelante que la Corte no ha precisado cómo, cuándo ni dónde se llegó al acuerdo tácito), permite entender por qué el Perú invocó a lo largo del proceso la sentencia del caso Nicaragua c. Honduras, en el extremo que señala que el «establecimiento de un límite marítimo permanente es una cuestión de gran importancia y el acuerdo no puede ser fácilmente presumido» ${ }^{18}$.

Ya que no existía instrumento jurídico expreso que Chile pudiera presentar y que el límite no podía ser fácilmente presumido, correspondería a Chile, no al Perú, demostrar la existencia del límite por 200 millas marinas y cuál era su fundamento legal. La propia Corte ha señalado que «es el litigante que busca establecer un hecho quien tiene la carga de la prueba de demostrarlo» ${ }^{19}$.

Estos elementos permiten poder afirmar que al inicio del proceso existió una absoluta incertidumbre acerca de qué título jurídico Chile invocaría para fundamentar la existencia del límite marítimo entre los dos Estados. De hecho, Chile no llegó a acertar en tal título jurídico, pues nunca argumentó ante la Corte que existiese un acuerdo tácito. 
Todos estos elementos permiten entender por qué el Perú se presentó a la Corte manteniendo la misma línea expresada en 1986 y 2004, es decir, que no existía ningún límite marítimo acordado entre los dos Estados. Incluso, no es difícil llegar a la conclusión de que esa era la única postura con la que el Perú se podía presentar a la Corte ante las circunstancias específicas del caso. Cualquier posición distinta hubiera significado aceptar, por lo menos, que existía un límite marítimo parcialmente, y solo hubiera estado fundamentada en algún argumento tan incierto como lo fue, hasta el final del caso, el acuerdo tácito. Tal posición no hubiera sido, además, sostenible en el plano político interno y hubiera automáticamente sido empleado contra el Perú por la otra parte en el caso, con resultados impredecibles.

Más aún, la referida postura del Perú estaba fundamentada en diversos argumentos legales, muchos de los cuales fueron aceptados por la Corte, como veremos más adelante.

\section{III.2. De Chile}

Cuando Chile presentó a la Corte por primera vez su argumentación legal en el caso, en su Contramemoria de marzo de 2010, optó por colocar como centro de toda su fundamentación jurídica sobre la existencia del límite marítimo a la Declaración de Santiago de 1952. Todos los demás instrumentos jurídicos que discutió o presentó, sean anteriores, contemporáneos o posteriores a 1952, servían para Chile para interpretar que en la Declaración se estableció un límite marítimo de doscientas millas marinas de extensión. En efecto, como afirmó en su Contramemoria, «[e]l caso de Chile es que Chile y el Perú delimitaron completa y definitivamente sus proyecciones marítimas en la Declaración de Santiago de 1952. Ese tratado debe ser leído junto con el Acuerdo de Lima de 1954 y en el contexto de las proclamaciones concordantes hechas por las Partes en $1947 \gg^{20}$.

En esta línea, Chile presentó a la Corte expresamente un caso sobre interpretación de tratados ${ }^{21}$. Y, en concreto, de un tratado: la Declaración de Santiago de 1952. Y de un artículo de la Declaración: el cuarto. Así, para Chile:

- Las proclamaciones de 1947 deben entenderse como circunstancias para la conclusión de la Declaración de Santiago, según la regla de interpretación complementaria del artículo 32 de la Convención de Viena sobre el Derecho de los Tratados de $1969^{22}$. 
- La Declaración de Santiago, en particular su punto IV, debe ser interpretada conforme al sentido corriente de sus términos, en su contexto y teniendo en cuenta su objeto y fin, según la regla general de interpretación del artículo 31 de la referida Convención de Viena ${ }^{23}$.

- Las actas de la Conferencia de Santiago donde se acordó la Declaración son parte de los trabajos preparatorios del tratado, a ser empleados para la interpretación de la Declaración según el artículo 32 de la misma Convención de Viena ${ }^{24}$.

- El Convenio sobre Zona Especial Fronteriza Marítima de 1954 complementa a la Declaración de Santiago y debe ser leído junto con ella. Es necesario para su interpretación, según Chile ${ }^{25}$.

- Los documentos de 1968 y 1969 sobre faros de enfilación son acuerdos ulteriores de las partes necesarios para interpretar la Declaración de Santiago según el artículo 31.3 a de la Convención de Viena de 1969.

- Toda (subráyese toda) la conducta posterior de las partes planteada por Chile es invocada en su argumentación legal ante la Corte como práctica ulteriormente seguida, que contiene el acuerdo de las partes sobre cómo interpretar la Declaración de Santiago, de acuerdo con el artículo 31.3.b de la indicada Convención de Viena.

Los argumentos complementarios de Chile sobre este tema, como la invocación al principio del pacta sunt servanda y de la estabilidad de las fronteras ${ }^{26}$, se referían directamente a que el límite marítimo de doscientas millas marinas pactado expresamente en 1952 debía ser respetado y mantenido por la Corte.

Chile mantuvo a lo largo de todo el proceso la misma argumentación sobre esta materia. No cambió la estructura general de su caso sobre la existencia del límite marítimo. Chile no presentó argumentos alternativos. No argumentó que pudiera haber una costumbre internacional bilateral; o una regional en el Pacífico sudamericano. No argumentó que el Perú hubiese otorgado su aquiescencia. No argumentó que el Perú estuviese impedido de presentar el caso debido a estoppel. No argumentó que hubiese un acuerdo de delimitación contenido en dos

23 Ibídem, párrafos 4.10-4.16 y 4.21-4.24.

24 Ibídem, párrafos 4.45-4.46.

25 Ibídem, párrafos 4.5-4.7.

26 "Controversia marítima (Perú c. Chile). Sentencia», párrafo 23. 
o más instrumentos conexos ${ }^{27}$. No argumentó que hubiese un acuerdo tácito.

El caso, tal como fue presentado por Chile, fue contestado por el Perú durante el resto del proceso ante la Corte y fue completamente rechazado por la CIJ. Es importante tener en cuenta esto, ya que cuando la Corte, por ejemplo, resume las posiciones generales de las partes en los párrafos 22 y 23 de la sentencia de enero de 2014 simplifica enormemente la argumentación de las partes ante la Corte. Es entendible que proceda así: después de todo, no tenía por qué referirse a cada elemento de la argumentación de los dos Estados, más aún cuando decidió rápidamente en su fallo que la Declaración de Santiago no estableció límite marítimo alguno.

\section{LA DISCUSIÓN SOBRE LA EXISTENCIA DEL LÍ- MITE MARÍTIMO}

El fallo del 27 de enero de 2014 dedica sus primeros 23 párrafos a relatar la historia procesal del caso (párrafos 1 a 12), a indicar cuáles fueron los pedidos de las partes (párrafos 13 a 15), a describir la geografía general de las costas de los dos Estados (párrafo 16), a explicar el contexto histórico (párrafos 17 a 21) y, finalmente, a presentar la visión panorámica de las posiciones de las partes a la que ya nos hemos referido (párrafos 22 a 23).

En el párrafo 24 se entra al primer tema a ser resuelto del fondo del asunto. La CIJ declara que «[p]ara poder resolver la controversia que tiene frente a sí, la Corte debe primero determinar si es que existe un límite marítimo, como Chile alega» ${ }^{28}$. A partir de ese momento y hasta el párrafo 99, la Corte se dedica a resolver esa cuestión. Encuentra que las partes reconocieron la existencia de un límite marítimo en un acuerdo tácito. Seguidamente, emplea del párrafo 100 al 151 a determinar el alcance y extensión de dicho límite. Concluye que no fue un límite por doscientas millas marinas de extensión, sino tan solo por ochenta. En este apartado del artículo abordaremos la decisión de la Corte sobre lo primero. En el siguiente, discutiremos la determinación del alcance y extensión del límite.

\section{IV.1. Las proclamaciones de 1947}

En 1947, Perú y Chile se encontraron entre los primeros Estados que proclamaron zonas marítimas de doscientas millas marinas de extensión, en una época en la que la costumbre internacional solo permitía a los Estados pequeñas zonas marítimas cercanas a sus costas. Chile lo hizo

ANÁLISIS DE LOS

PRINCIPALES

ELEMENTOS DE

LA SENTENCIA

DE LA CORTE

INTERNACIONAL

DE JUSTICIA EN

EL CASO DE LA

CONTROVERSIA

MARÍTIMA (PERÚ C.

CHILE) A LA LUZ DE

LAS POSICIONES

DE LAS PARTES

ANALYSIS OF

THE MAIN

ELEMENTS OF THE INTERNATIONAL

COURT OF JUSTICE

JUDGMENT IN THE

MARITIME DISPUTE

(PERU V. CHILE) IN

THE LIGHT OF THE

PARTIES POSITIONS 
mediante la Declaración Presidencial del 23 de junio de 1947 y el Perú a través de su decreto supremo 781 del 1 de agosto de ese año.

Cada una de esas proclamaciones establecía el criterio mediante el cual cada Estado proyectaba su zona marítima. La Declaración de Chile establecía en su artículo 3 la «protección y control sobre todo el mar comprendido dentro del perímetro formado por la costa con una paralela matemática proyectada en el mar a doscientas millas marinas de distancia de las costas continentales chilenas» ${ }^{29}$.

Por su parte, el artículo 3 del decreto supremo 781 señala que el Perú

[...] declara que ejercerá dicho control y protección sobre el mar adyacente a las costas del territorio peruano en una zona comprendida entre esas costas y una línea imaginaria paralela a ellas y trazada sobre el mar a una distancia de doscientas (200) millas marinas, medida siguiendo la línea de los paralelos geográficos ${ }^{30}$.

De esa manera, el Perú empleó para el trazado inicial de su zona marítima el método conocido como el tracéparallèle. Chile argumentó que «la zona marítima del Perú fue concebida en 1947 como un corredor limitado por dos paralelos de latitud, extendiéndose hacia el oeste por una distancia mínima de 200 millas marinas» ${ }^{31}$. Más aún, que «la reclamaciones unilaterales formuladas por las Partes en 1947 eran concordantes» y que «dichas reclamaciones fueron confirmadas en 1952 a través de un acuerdo internacional multilateral, la Declaración de Santiago» ${ }^{32}$.

Las proclamaciones de 1947 cumplían un rol central en la argumentación de Chile ante la Corte (aunque no el principal), ya que la Declaración de Santiago no establece la forma de medir la zona marítima de doscientas millas marinas de cada Estado signatario. Por eso, Chile insistió tanto en lo siguiente: «Históricamente, existe una línea directa de parentesco que vincula a la Declaración de Santiago con el reclamo del Perú de 200M [millas marinas] de 1947 [...]. Conceptualmente, los Estados partes de la Declaración de Santiago adoptaron los límites laterales que se derivaron de la concepción del Perú de su zona marítima» ${ }^{33}$. A esto añadió que

cinco años después, en la Conferencia de Santiago de 1952, las Partes actuaron sobre la base concordante de que sus zonas marítimas respectivas estaban limitadas por un paralelo de latitud. La cuestión de los límites laterales de las zonas marítimas de los Estados partes de la Declaración de Santiago fue, por tanto, no controvertida. 
[...] la cuestión de los límites marítimos laterales podía ser, y de hecho fue, abordada en términos sumarios en la Declaración de Santiago ${ }^{34}$.

Así como que

[...] la significación principal de las proclamaciones de 1947 en este caso es como antecedentes del acuerdo de límites marítimos de las Partes. Así, cuando Chile y el Perú llegaron a concluir la Declaración de Santiago en 1952, sus zonas marítimas colindaban, pero no se superponían. La delimitación de las zonas marítimas generadas por las costas continentales fue, por tanto, un ejercicio directo y no controvertido cuando fue realizado en 1952 y confirmado en 1954 en acuerdos internacionales tripartitos que establecieron reclamaciones de 200M [millas marinas]. Entre el Perú y Chile la delimitación consistió en confirmar la línea divisoria de sus reclamaciones unilaterales que no se superponían ${ }^{35}$.

El Perú respondió a estas afirmaciones con una serie de argumentos. Entre ellos, Sir Michal Wood afirmó ante la Corte que el «hecho de que los paralelos geográficos fueron empleados para construir un tracé parallèle de ninguna manera significó que los paralelos pretendían convertirse en límites unilaterales. Los paralelos no fueron más que líneas de construcción geométricas» ${ }^{36}$. La Corte aceptó completamente ese argumento del Perú y lo emplea en su sentencia, aunque no menciona que el argumento lo planteó directamente el Perú. Así, para la CIJ, «la utilización de dicho método [el tracé parallèle] no es suficiente para evidenciar una clara intención de las Partes de que su eventual límite marítimo sería un paralelo» ${ }^{37}$.

El Perú también afirmó repetidas veces que las proclamaciones de 1947 fueron de carácter tentativo, no definitivo ${ }^{38}$, y que fueron realizadas con la intención expresa de ser modificadas en el futuro. En efecto, el artículo 3 de la Declaración de Chile y el artículo 3 del decreto supremo peruano expresamente prevén la posibilidad de que la zona establecida por cada Estado sea modificada en el futuro. La Declaración chilena podría ser modificada, según su artículo 3, «cada vez que el Gobierno lo crea conveniente, sea ratificando, ampliando o de cualquier manera modificando dichas demarcaciones, conforme a los conocimientos, descubrimientos, estudios e intereses de Chile que sean advertidos en el futuro» ${ }^{39}$. El decreto supremo peruano, según su artículo 3, establece que «el Estado se reserva el derecho [...] de modificar dicha demarcación

ANÁLISIS DE LOS PRINCIPALES

ELEMENTOS DE

LA SENTENCIA

DE LA CORTE

INTERNACIONAL

DE JUSTICIA EN

EL CASO DE LA

CONTROVERSIA

MARÍTIMA (PERÚ C.

CHILE) A LA LUZ DE

LAS POSICIONES

DE LAS PARTES

ANALYSIS OF

THE MAIN

ELEMENTS OF THE INTERNATIONAL

COURT OF JUSTICE JUDGMENT IN THE MARITIME DISPUTE (PERU V. CHILE) IN THE LIGHT OF THE PARTIES POSITIONS 
de acuerdo con las circunstancias sobrevinientes por razón de los nuevos descubrimientos, estudios, o intereses nacionales que fueran advertidos en el futuro» ${ }^{40}$.

En ambos instrumentos, el término «demarcación» no significa una mera señalización, sino el verdadero establecimiento de la zona en sí. Así argumentó el Perú ante la Corte ${ }^{41}$ y así aceptó completamente la CIJ al determinar que «el párrafo 3 de la Declaración de Chile prevé el establecimiento de zonas de protección [...] considerando que estas pueden ser modificadas de cualquier manera» según los intereses y necesidades de Chile en el futuro ${ }^{42}$. Asimismo, el «lenguaje del Decreto del Perú de 1947 es igualmente condicional. En el párrafo 3 el Perú se reserva el derecho de modificar sus "zonas de control y protección" ${ }^{43}$.

La Corte, entonces, rechazó completamente la argumentación de Chile sobre cómo entender las proclamaciones de 1947 y empleó directamente en su sentencia los argumentos que el Perú proporcionó. Es de notar que la tesis de Chile según la cual en virtud de las proclamaciones de 1947 Perú y Chile empezaron a emplear un paralelo geográfico que más adelante se convertiría en un límite marítimo definitivo fue rechazada de plano por la Corte, debido a la naturaleza provisional de ambas proclamaciones ${ }^{44}$. En tal sentido, tampoco se puede afirmar que a raíz de esas proclamaciones surgió una costumbre bilateral, regional u otro argumento similar ${ }^{45}$. El decreto supremo de 1947 no generó ningún límite lateral en un paralelo geográfico que el Perú haya estado obligado a emplear en el plano internacional.

\section{IV.2. La Declaración de Santiago de 1952}

Tal como hemos visto, el núcleo de la argumentación de Chile en el caso fue que el punto IV de la Declaración de Santiago estableció un límite marítimo por doscientas millas marinas de extensión y que la Corte no tenía nada que delimitar. Si bien el Perú rechazó esta posición, la contradijo en el caso y, finalmente, la Corte la rechazó también en su sentencia, ella no debe ser menospreciada.

El punto II de la Declaración de Santiago establece que «los Gobiernos de Chile, Ecuador y Perú proclaman como norma de su política internacional marítima, la soberanía y jurisdicción exclusivas que a

40 Ibídem, párrafo 4.51

41 CR 2012/27, p. 64.

42 "Controversia marítima (Perú c. Chile). Sentencia», párrafo 41. Las cursivas son nuestras.

43 Ibídem, párrafo 42 . Las cursivas son nuestras.

44 lbídem, párrafos 40-42.

45 Ver ABUGATTÁs, Gattas. «Análisis sobre la referencia a los acuerdos tácitos en algunos casos sobre delimitación marítima, con especial atención al asunto de la delimitación marítima entre Perú y Chile». Agenda Internacional, XXI, 32 (2014), pp. 102ss (http://revistas.pucp.edu.pe/index.php/ agendainternacional/article/viewFile/9878/10294). 
cada uno de ellos corresponde sobre el mar que baña las costas de sus respectivos países, hasta una distancia mínima de 200 millas marinas desde las referidas costas» ${ }^{46}$.

Si la Corte llegaba a determinar que existía un límite marítimo acordado que estuviese vinculado o se derivase de alguna manera de la Declaración de Santiago, entonces podría haber concluido que el límite se extendía por las doscientas millas marinas de la zona reclamada en la Declaración de Santiago. Esa fue, en efecto, la posición de cinco jueces de la Corte que no votaron con la mayoría en los puntos 3 y 4 de la parte resolutiva del fallo.

Los puntos de vista minoritarios de esos cinco jueces son relevantes porque muestran lo que ellos deben haber sostenido durante las deliberaciones de la Corte, evidenciando lo que estuvo en juego en el caso. Para Xue, Gaja, Bandhari y Orrego Vicuña:

De acuerdo con el párrafo II de la Declaración de Santiago, las reclamaciones de Chile, Ecuador y Perú se refirieron a una zona que se extendía hasta una distancia mínima de 200 millas marinas de sus costas [...]. Aunque esas reclamaciones difícilmente podrían tener un fundamento en el derecho internacional consuetudinario en el momento en que fueron hechas, una delimitación podría haber sido acordada por los tres Estados incluso respecto a sus derechos potenciales. Se puede argumentar que eso fue hecho en la Declaración de Santiago ${ }^{47}$.

Por su parte, el juez Tomka también mencionó expresamente el punto II de la Declaración al hacer conocer su punto de vista personal en el caso, añadiendo que en la década de 1950 las partes «resolvieron legalmente el asunto de la delimitación lateral de sus zonas de "soberanía" exclusiva y jurisdicción, como las habían declarado separadamente cada una de ellas en 1947 y conjuntamente en 1952» ${ }^{48}$.

Además de estos cinco jueces, el ruso Skotnikov, quien votó con la mayoría de diez jueces que decidieron que el paralelo del límite marítimo solo llegó a ochenta millas marinas de la costa, consideró necesario dejar constancia de su punto de vista, según el cual no le pareció «convincente» la lógica de la Corte por la cual concluyó «que el límite marítimo acordado no se extiende por la totalidad de las zonas marítimas reclamadas unilateralmente a través de las Proclamaciones de 1947 y luego establecidas en la Declaración de Santiago de 1952» ${ }^{49}$.

ANÁLISIS DE LOS PRINCIPALES

ELEMENTOS DE

LA SENTENCIA

DE LA CORTE

INTERNACIONAL

DE JUSTICIA EN

EL CASO DE LA

CONTROVERSIA

MARÍTIMA (PERÚ C.

CHILE) A LA LUZ DE

LAS POSICIONES

DE LAS PARTES

ANALYSIS OF

THE MAIN

ELEMENTS OF THE INTERNATIONAL

COURT OF JUSTICE

JUDGMENT IN THE

MARITIME DISPUTE

(PERU V. CHILE) IN

THE LIGHT OF THE PARTIES POSITIONS 
En resumen, la Corte rechazó la tesis chilena sobre la Declaración de Santiago pero cinco jueces llegaron a no unirse a la mayoría de diez porque le dieron un rol central a la Declaración de Santiago. Casi se les une un sexto miembro de la Corte. ¿Qué hubiese ocurrido si el Perú no se hubiese opuesto decididamente a lo largo de todos sus alegatos escritos y orales a la posición general de Chile en el caso? Este no es un ejercicio de especulación, por supuesto, pero se puede apreciar que, en efecto, la posición de Chile llegó a convencer a un número no despreciable de miembros de la Corte, incluyendo a su actual presidente.

Por otro lado, la sentencia toma nota de la discusión inicial que tuvieron las partes acerca de si, en el momento de su suscripción, la Declaración tuvo el carácter de tratado internacional ${ }^{50}$. El profesor Alain Pellet aclaró en las audiencias orales que «nosotros no contestamos que la declaración deba, hoy en día, ser considerada como un tratado (el profesor Dupuy [abogado de Chile], otro oponente y amigo, se ha preocupado mucho, en vano, de demostrar este punto que ya no nos divide) $\aleph^{51}$. Fue sobre la base de esto que, en el fallo, se señala que «la Corte observa que ya no se discute que la Declaración de Santiago de 1952 sea un tratado internacional. La labor de la Corte ahora es determinar si es que estableció un límite marítimo entre las Partes» ${ }^{52}$.

En otras palabras, la Corte no entrará necesariamente a evaluar aquellos puntos no discutidos por las partes y puede darlos por sentado, como hizo en el caso comentado. Así, toda la extensa posición de Chile sobre la Declaración de Santiago y todo el complejo caso de interpretación de tratados en el que consistió su argumentación ante la Corte merecía ser fuertemente contestado, como efectiva y exitosamente hizo el Perú.

Respecto a si el punto IV de la Declaración estableció un límite marítimo entre el Perú y Chile, dicho párrafo señala lo siguiente:

En el caso de territorio insular, la zona de 200 millas marinas se aplicará en todo el contorno de la isla o grupo de islas. Si una isla o grupo de islas pertenecientes a uno de los países declarantes estuviere a menos de 200 millas marinas de la zona marítima general que corresponde a otro de ellos, la zona marítima de esta isla o grupo de islas quedará limitada por el paralelo del punto en que llega al mar la frontera terrestre de los Estados respectivos ${ }^{53}$.

Chile invocó ante la Corte los artículos 31 y 32 de la Convención de Viena sobre Derecho de los Tratados de 1969, en el sentido indicado en el punto 3.2 de este artículo, vale decir, que todos los instrumentos

50 «Controversia marítima (Perú c. Chile). Sentencia», párrafos 46-48.

51 CR 2012/34, p. 34.

52 «Controversia marítima (Perú c. Chile). Sentencia», párrafo 48.

53 Las cursivas son nuestras. 
relevantes previos, contemporáneos o posteriores a la Declaración (Proclamaciones de 1947, Actas de la Conferencia de 1952, otros acuerdos celebrados en esa Conferencia, el Convenio sobre Zona Especial Fronteriza Marítima de 1954, etcétera), así como toda la práctica de las partes en el caso, sirve en el caso de Chile solo para interpretar que la Declaración fijó un límite marítimo. La Corte, en solo trece párrafos del fallo (58 a 70) y mediante un ejercicio de interpretación de tratados, rechazó por completo la posición chilena, empleando argumentos invocados todos por el Perú. Así:

- Primero interpretó la Declaración sobre la base del sentido corriente que ha de atribuirse a sus términos según la regla del artículo 31.1 de la Convención de Viena. Una vez llegado a su punto IV, declaró que «es el único en la Declaración de Santiago que hace alguna referencia a los límites de las zonas marítimas de los Estados partes», pero que «guarda silencio sobre los límites laterales de las zonas marítimas que no se derivan de los territorios insulares ${ }^{54}$. Ese fue el principal argumento del Perú respecto a la Declaración, por supuesto, durante todo el proceso, en tanto en 1952 las partes no consideraban que existiesen islas relevantes entre ellas para los propósitos de ese artículo ${ }^{55}$ y también la razón por la que el caso entero de Chile fue sorprendente para muchos.

- Chile también argumentó que el punto IV de la Declaración no se entiende bien si solo se considera que delimitó las zonas marítimas de las islas: debió entonces establecer o presuponer que existía un límite marítimo general. Este argumento fue compartido por cinco jueces ${ }^{56}$, pero no por la mayoría de la Corte. La CIJ declaró, como institución, que ella «no está convencida por el argumento de Chile» ${ }^{57}$. El Perú demostró por qué ${ }^{58}$.

- La Corte también analiza el objeto y fin de la Declaración bajo la misma regla del artículo 31.1 de la Convención de Viena de 1969. La CIJ identifica bien el objeto y fin que atribuyen las partes a la Declaración (para Chile: identificar los perímetros de las zonas marítimas de las partes). Chile también afirmó, específicamente, que delimitar las zonas entre los Estados partes fue parte del

54 «Controversia marítima (Perú c. Chile). Sentencia», párrafo 60.

55 A manera de muestra: MP, párrafo 4.77; RP, párrafos 3.69-3.72; CR 2012/28, pp. 13-14 (http://www. icj-cij.org/docket/files/137/17206.pdf).

56 «Controversia marítima (Perú c. Chile). Opinión disidente conjunta de los jueces Xue, Gaja, Bhandari y el juez ad hoc Orrego Vicuña», párrafo 5; «Controversia marítima (Perú c. Chile). Declaración del Presidente Tomka», párrafo 22.

57 «Controversia marítima (Perú c. Chile). Sentencia», párrafo 61.

58 A manera de muestra: RP, párrafos 3.83-3.99; CR 2012/28, p. 45.

ANÁLISIS DE LOS

PRINCIPALES

ELEMENTOS DE

LA SENTENCIA

DE LA CORTE

INTERNACIONAL

DE JUSTICIA EN

EL CASO DE LA

CONTROVERSIA

MARÍTIMA (PERÚ C.

CHILE) A LA LUZ DE

LAS POSICIONES

DE LAS PARTES

ANALYSIS OF

THE MAIN

ELEMENTS OF THE

INTERNATIONAL

COURT OF JUSTICE

JUDGMENT IN THE

MARITIME DISPUTE

(PERU V. CHILE) IN

THE LIGHT OF THE

PARTIES POSITIONS 
objeto y fin de la Declaración ${ }^{59}$. La Corte claramente descarta la argumentación de Chile ${ }^{60}$.

- La CIJ se refiere a las Minutas de la Conferencia de Santiago de 1952. Chile dio muchísima importancia en todos sus alegatos escritos y orales a dichos documentos, argumentando que permiten comprender su posición sobre la Declaración ${ }^{61}$. El fallo no refleja la importancia de esos textos para la argumentación de Chile. Chile los invocó como acuerdos celebrados por las partes con motivo de la celebración de la Declaración y, por tanto, pidió que se empleen como parte del método general de interpretación de tratados del artículo 31 de la Convención de Viena. El Perú los descartó como parte del método general y observó que, en realidad, eran de importancia secundaria por ser simples trabajos preparatorios ${ }^{62}$. La Corte, rápidamente, los califica efectivamente como travaux préparatoires y les niega relevancia para la interpretación de la Declaración ${ }^{63}$, salvo por el hecho de que pueden ser empleados para confirmar el resultado del método principal de interpretación. Seguidamente, ideclara que confirman que en la Declaración no se pactó ningún límite marítimo ${ }^{64}$, tal como el Perú argumentó!

De la manera antes señalada, en los primeros setenta párrafos del fallo, la Corte dejó de lado el grueso de la argumentación chilena. Varios de los jueces hicieron comentarios sobre lo ocurrido. Para Owada, ex presidente de la Corte, «Chile ha mantenido consistentemente su posición de que la Declaración de Santiago fue la base legal, es decir, fons et origo, del límite marítimo», pero que la «Sentencia, muy correctamente desde mi punto de vista, ha rechazado esta posición, tanto en materia de interpretación de las disposiciones de la Declaración como sobre la base de su historia legislativa revelada en los travaux préparatoires» ${ }^{65}$.

Para Sebutinde, «[a]plicandolos principios establecidos de interpretación de tratados a la Declaración de Santiago y en particular a su Artículo IV, la Corte rechaza el fundamento mismo de la reclamación de Chile» ${ }^{66}$. Incluso el presidente Tomka, quien estuvo a favor de que la Corte determine que existió un límite marítimo por doscientas millas marinas, reconoce que «[s]ería, sin embargo, ir demasiado lejos afirmar que la Declaración expresamente estableció el paralelo como límite entre las

59 CMC, párrafo 4.22.

60 «Controversia marítima (Perú c. Chile). Sentencia», párrafo 63.

$61 \mathrm{CMC}$, párrafos 2.78, 2.99, 2.105, 2.192-2.193 y 4.45-4.46; DC, párrafos 2.53-2.56, 2.125, 7.8, 7.11,

7.15 y 8.3; CR 2012/32, pp. 29-30, 49-51 (http://www.icj-cij.org/docket/files/137/17216.pdf).

62 CR 2012/28, pp. 18-22; CR 2012/33, pp. 24-25 (http://www.icj-cij.org/docket/files/137/17218.pdf).

63 «Controversia marítima (Perú c. Chile). Sentencia», párrafo 65.

64 lbídem, párrafo 66.

65 «Controversia marítima (Perú c. Chile). Opinión separada del Juez Owada», párrafo 7.

66 «Controversia marítima (Perú c. Chile). Opinión disidente de la Jueza Sebutinde», párrafo 3. 
zonas de Chile y Perú, respectivamente. El párrafo IV de la Declaración se limita al "caso de territorio insular" ${ }^{67}$.

\section{IV.3. El Convenio sobre Zona Especial Fronteriza Marítima de 1954}

Entre los tratados celebrados por Perú, Chile y Ecuador en 1954 que las partes en el caso discutieron y que la Corte analizó en su sentencia (párrafos 71 a 98), sin duda el más relevante y el que influyó determinantemente en la decisión de la Corte fue el Convenio sobre Zona Especial Fronteriza Marítima de 1954 (en adelante, simplemente el «Convenio de 1954», párrafos 80 a 98 del fallo).

El agente del Perú en el caso ha señalado recientemente que:

Nosotros habíamos identificado, desde el inicio, que el Convenio de 1954 constituía un elemento difícil de manejar por su mención al paralelo como límite marítimo, por lo que buscamos acotarlo en nuestros alegatos, incidiendo en que este acuerdo tuvo carácter provisional y específico, en la medida que estaba dirigido a evitar incidentes y multas a pescadores que tenían escasos conocimientos de náutica, con embarcaciones de pequeño porte y que no poseían instrumental para ubicarse correctamente en el mar, por lo que faenaban cerca de la costa y, por tanto, la zona de tolerancia montada en el paralelo no podía extenderse a gran distancia y mucho menos hasta las doscientas milla ${ }^{68}$.

En concreto, el referido Convenio señala lo siguiente en el primer párrafo de sus considerandos:

Que la experiencia ha demostrado que debido a las dificultades que encuentran las embarcaciones de poco porte tripuladas por gente de mar con escasos conocimientos de náutica o que carecen de los instrumentos necesarios para determinar con exactitud su posición en alta mar, se producen con frecuencia, de modo inocente y accidental, violaciones de la frontera marítima entre los Estados vecinos.

Mientras que su artículo primero determina lo siguiente: «Establécese [sic] una Zona Especial, a partir de las 12 millas marinas de la costa, de 10 millas marinas de ancho a cada lado del paralelo que constituye el límite marítimo entre los dos países».

Estas dos referencias a una frontera o límite marítimo hacían, por supuesto, difícil de manejar este tratado internacional en el caso, como

67 «Controversia marítima (Perú c. Chile). Declaración del Presidente Tomka», párrafo 13.

68 NovAK, Fabián. «Entrevista al embajador Allan Wagner, agente del Estado peruano en el diferendo marítimo entre el Perú y Chile ante la Corte Internacional de Justicia». Agenda Internacional, XXI, 32 (2014), p. 16 (http://revistas.pucp.edu.pe/index.php/agendainternacional/article/view/9875/10291). Las cursivas son nuestras.

ANÁLISIS DE LOS PRINCIPALES

ELEMENTOS DE

LA SENTENCIA

DE LA CORTE

INTERNACIONAL

DE JUSTICIA EN

EL CASO DE LA

CONTROVERSIA

MARÍTIMA (PERÚ C.

CHILE) A LA LUZ DE

LAS POSICIONES

DE LAS PARTES

ANALYSIS OF

THE MAIN

ELEMENTS OF THE

INTERNATIONAL

COURT OF JUSTICE

JUDGMENT IN THE

MARITIME DISPUTE

(PERU V. CHILE) IN

THE LIGHT OF THE

PARTIES POSITIONS 
ha señalado el embajador Wagner. Sin embargo, el Perú planteó en su Memoria y Chile aceptó en su Contramemoria que ese tratado en sí no estableció un límite marítimo ${ }^{69}$. Tal vez hoy pueda parecer eso secundario o evidente, pero no se debe olvidar que, cuando el Perú planteó el caso y elaboró su Solicitud y su Memoria, no se conocía con exactitud cómo fundamentaría Chile su posición sobre la existencia del límite marítimo. Por ejemplo, puede parecer evidente hoy que la Declaración de Santiago no estableció límite marítimo alguno, como el Perú planteó en su Memoria, pero aun así Chile afirmó lo contrario en su Contramemoria e insistentemente durante el resto del caso. Por otro lado, sí existía una posibilidad real de que Chile fundamente la existencia del límite marítimo en el Convenio de 1954. No debe olvidarse que, como hemos ya comentado, en 2004 Chile afirmó que existían «convenios» (en plural) que establecieron el límite, posición abandonada durante el proceso ante la Corte.

Entonces, si el Perú presentaba su caso ante la Corte y la convencía de que 1) en 1947 no se pactó límite marítimo alguno y las zonas ahí establecidas solo fueron provisionales, 2) en 1952 no se pactó límite marítimo alguno entre el Perú y Chile y, por lo tanto, la referencia a la «distancia mínima» de doscientas millas en su punto II era neutralizada y 3) en el Convenio de 1954 no se pactó límite marítimo alguno y la zona de tolerancia ahí contenida no se extendió por doscientas millas marinas, el Perú contaría con una buena posibilidad de obtener un resultado positivo en el caso. En otras palabras, el Perú no tenía por qué dejar de presentar el caso o esperar un resultado negativo sobre la base del contenido del Convenio de 1954: el Convenio era difícil de manejar pero podía ser manejado.

Lo que resultó determinante, finalmente, sobre el Convenio de 1954 fue que la Corte decidió algo que las partes no habían discutido expresamente en el caso: que ahí se reconoció un acuerdo tácito. Tal vez hoy se pueda pensar cómodamente y en retrospectiva que entonces el Perú debió discutir específica y detalladamente la posibilidad de que la Corte encuentre un acuerdo tácito reconocido en 1954. Sin embargo, hemos comentado ya en la sección 3.2 como existieron una serie de múltiples líneas argumentativas que Chile pudo seguir en el caso pero no siguió, ni principal ni alternativamente.

El Perú podía abordar de manera general esas posibilidades, pero no cada una de ellas específica o detalladamente. No hubiera sido factible y podría haber sido contraproducente. Por ejemplo, Chile no argumentó que el límite esté fundamentado en una costumbre internacional, sea bilateral o regional. El Perú no entró en detalle entonces, de manera específica, 
a argumentar que en el caso no se presentaron los elementos específicos que conforman la costumbre internacional a título de tal, pero sí negó, por ejemplo, que la práctica haya sido generalizada, por doscientas millas, etcétera. Si el Perú hubiese entrado en detalle y extensamente a una discusión no planteada sobre la costumbre internacional, conociendo las tácticas de los abogados que litigan ante la Corte, no es difícil de imaginar que automáticamente Chile hubiera empezado a afirmar que el Perú estaba preocupado por la posibilidad de que haya una costumbre y haya empezado a abordar directa y ampliamente esa posibilidad, complicando más el caso, el cual, como se ha afirmado ya, era de por sí bastante complejo.

No debe olvidarse que el Perú fue el Estado demandante y ello significa que a cada alegato escrito y oral del Perú siempre le siguió un alegato escrito u oral del demandado, Chile. A la Memoria le siguió la Contramemoria. A la Réplica, la Dúplica. A la primera ronda de alegatos orales del Perú, la primera ronda de Chile. A la segunda ronda del Perú, la segunda de Chile. De esa manera, si el Perú se adentraba en detalle, específicamente, a cualquiera de las líneas argumentativas posibles que Chile no planteó, ello podría generar una reacción contraproducente: Chile tendría tiempo y oportunidad de desarrollar con detalle su posición, extenderse ante la Corte y dar nuevos o mayores argumentos a la Corte, los que eventualmente esta podría haber considerado. Luego de la segunda ronda oral de Chile, el Perú ya no tendría oportunidad de responder.

Por otro lado, respecto al Convenio de 1954, el Perú brindó múltiples argumentos con el objetivo, como ha afirmado el embajador Wagner, de «acotarlo». Uno de ellos resultó fundamental para el resultado final del caso: el Convenio de 1954 no creó una zona de tolerancia que se extienda por doscientas millas marinas, por lo tanto, el acuerdo tácito no se extendió a lo largo de esa distancia.

Al respecto, Chile argumentó durante todo el proceso que el Convenio de 1954 tuvo una aplicación de doscientas millas marinas. En su Contramemoria graficó hasta dónde postulaba que se extendía la zona de tolerancia, con una visión incluso más expansiva de la misma ${ }^{70}$. En su Dúplica, no deja dudas acerca de su posición: «la zona de tolerancia (o zona de amortiguamiento [buffer zone]) no comenzó hasta la milla marina 12 de las costas de las partes. Luego prosiguió a la totalidad de la extensión de 200 millas de la zona marítima de cada una» ${ }^{71}$.

El Perú, en cambio, con la intención que ha mencionado el embajador Wagner de acotar el efecto del Convenio, el cual planteaba serias

ANÁLISIS DE LOS

PRINCIPALES

ELEMENTOS DE

LA SENTENCIA

DE LA CORTE

INTERNACIONAL

DE JUSTICIA EN

EL CASO DE LA

CONTROVERSIA

MARÍTIMA (PERÚ C.

CHILE) A LA LUZ DE

LAS POSICIONES

DE LAS PARTES

ANALYSIS OF

THE MAIN

ELEMENTS OF THE

INTERNATIONAL

COURT OF JUSTICE

JUDGMENT IN THE

MARITIME DISPUTE

(PERU V. CHILE) IN

THE LIGHT OF THE

PARTIES POSITIONS 
dificultades al Perú, postuló que solo se extendió a la cercanía de la costa. La posición del Perú sobre la extensión que alcanzaba la zona de tolerancia contemplada en el Convenio fue resumida por sir Michael Wood durante las audiencias orales, la mañana del 4 de diciembre de 2012:

[L]a zona no fue graficada en mapas. El Convenio no contiene ninguna referencia a la extensión geográfica de la zona especial en dirección al mar. No existe mención en ninguna parte en el Convenio sobre una zona especial que se extienda hacia el mar por 200 millas marinas. La zona solo fue concebida como relevante por una corta distancia más allá de las 12 millas, donde los pescadores basados en la costa pescaban. Resulta completamente anacrónico pensar que este arreglo práctico de naturaleza provisional fue hecho en 1954 para aplicarse a lo largo de las 200 millas marinas $^{72}$.

La Corte aceptó la posición del Perú sobre la no extensión de la zona de tolerancia por doscientas millas marinas ${ }^{73}$. Ello podría parecer hoy evidente, pero Chile lo negó durante el proceso. En tanto el objetivo era «acotar» el alcance del Convenio de 1954, como ha indicado el embajador Wagner, este argumento peruano, aparentemente secundario para quien lo observe desde la distancia hoy, tuvo durante el caso un rol importante (no en vano el Perú se explayó sobre él deliberadamente) y llegó a ser determinante para que el límite marítimo alcanzado mediante un acuerdo tácito no se extienda por doscientas millas marinas, como se verá más adelante.

\section{IV.4. El acuerdo tácito}

\section{IV.4.1. Reconocimiento de un acuerdo tácito}

La Corte centra su análisis en el texto del Convenio de 1954 para determinar si existió un límite marítimo acordado entre el Perú y Chile, llegando a la siguiente conclusión: «En esa materia, los términos del Convenio sobre Zona Especial Fronteriza Marítima de 1954, especialmente su Artículo 1 leído con los párrafos que sirven de preámbulo, son claros. Ellos reconocen en un acuerdo internacional vinculante que un límite marítimo ya existe» ${ }^{74}$.

Luego, continúa la Corte:

El Convenio sobre Zona Especial Fronteriza Marítima de 1954 no indica cuándo y por qué medios se acordó dicho límite. El reconocimiento expreso de su existencia solo puede reflejar un acuerdo tácito al cual ellos 
habían llegado antes. Al respecto, la Corte ya ha mencionado que ciertos elementos de las Proclamaciones de 1947 y de la Declaración de Santiago de 1952 sugerían un entendimiento progresivo entre las Partes sobre su límite marítimo (ver los párrafos 43 y 69 anteriores). En un caso anterior la Corte reconoció que «[e]l establecimiento de un límite marítimo permanente es una cuestión de grave importancia», subrayando que «[l]a evidencia de un acuerdo legal tácito debe ser convincente» (Controversia Territorial y Marítima entre Nicaragua y Honduras en el Mar Caribe (Nicaragua c. Honduras), Sentencia, I.C.J. Reports 2007 (II), p. 735, párrafo 253). En este caso, la Corte tiene frente a sí un Convenio que deja en claro que el límite marítimo a lo largo de un paralelo ya existía entre las Partes. El Convenio de 1954 es decisivo en este aspecto. El Convenio refuerza el acuerdo tácito» ${ }^{75}$.

Pero también, inmediatamente después, clara y expresamente, determina que «[e]l Convenio sobre Zona Especial Fronteriza Marítima de 1954 no da ninguna indicación sobre la naturaleza del límite marítimo. Tampoco indica su extensión, excepto que sus disposiciones dejan en claro que el límite marítimo se extiende más allá de las 12 millas marinas de la costa» ${ }^{76}$.

Para la Corte, entonces, el texto del Convenio de 1954 «solo puede reflejar un acuerdo tácito». La Corte decide por descarte. En su decisión fue el texto (solo el texto) del Convenio de 1954 lo que primó, a pesar de que, como se advierte de inmediato, no se sabe ni se puede saber en qué momento o cómo se llegó al acuerdo tácito.

De esa manera, la Corte no aceptó el argumento peruano en el sentido de que nunca se acordó, mediante ningún tipo de acuerdo o por otra forma, un límite marítimo entre el Perú y Chile. Vale la pena recordar, sin embargo, que solo esa podía ser la posición del Perú ante la Corte en el caso, debido a las circunstancias concretas del mismo (ver apartado 3).

Por otro lado, la decisión de la Corte de determinar que las partes reconocieron un acuerdo legal tácito en 1954 no estuvo fundamentada en ningún argumento legal específico planteado por Chile durante el proceso. Para Chile, el Convenio de 1954 confirmaba el límite acordado en la Declaración de Santiago por doscientas millas marinas.

Resulta fundamental tomar nota de que la decisión de la Corte en los párrafos 91 y 92 de su fallo, arriba transcritos, está basada expresa, clara y únicamente para la Corte en el texto del Convenio de 1954, que fue «decisivo» al respecto, que «refuerza» el acuerdo tácito (y no está basado

ANÁLISIS DE LOS PRINCIPALES

ELEMENTOS DE

LA SENTENCIA

DE LA CORTE

INTERNACIONAL

DE JUSTICIA EN

EL CASO DE LA

CONTROVERSIA

MARÍTIMA (PERÚ C.

CHILE) A LA LUZ DE

LAS POSICIONES

DE LAS PARTES

ANALYSIS OF

THE MAIN

ELEMENTS OF THE

INTERNATIONAL

COURT OF JUSTICE

JUDGMENT IN THE

MARITIME DISPUTE

(PERU V. CHILE) IN

THE LIGHT OF THE

PARTIES POSITIONS 
en una práctica de las partes, por ejemplo). Ello va directamente de la mano de la decisión de la Corte de que el referido Convenio no aclara la extensión del límite preexistente. Esto es lo que hizo que la Corte luego tenga que determinar por otros medios cuál fue la extensión del límite acordado tácitamente.

Para la Corte, entonces, la misma base legal que permite determinar que hubo un acuerdo tácito, es decir, el texto del Convenio de 1954, es la que permite limitar la extensión del paralelo a menos de doscientas millas marinas. Ello solo fue posible porque, como también argumentó el Perú, ni las Proclamaciones de 1947, ni la Declaración de Santiago de 1952 (ique se refieren a zonas marítimas de doscientas millas marinas!) estuvieron relacionadas a un límite marítimo bilateral, vinculante, entre el Perú y Chile.

En resumen, hasta este momento:

- Las Proclamaciones de 1947 con sus zonas de doscientas millas marinas no son relevantes para la determinación de un límite marítimo entre el Perú y Chile, como el Perú argumentó y Chile negó.

- La Declaración de Santiago de 1952, con su zona marítima de doscientas millas marinas, no estableció ni fue relevante para la determinación de un límite marítimo entre el Perú y Chile, como el Perú argumentó y Chile negó.

- El Convenio sobre Zona Especial Fronteriza Marítima de 1954, pero únicamente su texto como la Corte expresamente señala, reconoció la existencia de un acuerdo legal tácito, posibilidad que ni Chile ni Perú argumentaron ante la Corte. Sin embargo, el Convenio no se extiende por doscientas millas marinas como el Perú argumentó y Chile negó.

- Todo lo anterior es lo que permite que la Corte determine que el límite reconocido en el acuerdo legal tácito tenga una extensión menor de doscientas millas marinas.

- Todo lo anterior tiene una base legal cuya mayor parte (salvo la posibilidad de que exista un acuerdo tácito) puede ser rastreada directamente hasta los argumentos de las partes en el caso.

\section{IV.4.2. El acuerdo tácito para la Corte Internacional de Justicia}

Este ha sido el primer caso en el que la Corte Internacional de Justicia ha determinado que existió un acuerdo legal tácito entre dos Estados, pero no es la primera ocasión en la que la Corte ha contemplado dicha posibilidad. De hecho, lo ha hecho en diversos casos en el pasado. 
Por ejemplo, el año 2002, en su sentencia sobre el fondo del caso terrestre y marítimo entre Camerún y Nigeria, la CIJ señaló que:

En general, se desprende de la jurisprudencia que, aunque la existencia de un acuerdo expreso o tácito entre las partes sobre la ubicación de sus respectivas concesiones petroleras puede indicar un consenso sobre las áreas marítimas sobre las que tienen derechos, las concesiones petroleras no son consideradas por sí mismas como circunstancias relevantes que justifiquen el ajuste o la modificación de la línea de delimitación provisional. Solo si están basadas en un acuerdo expreso o tácito entre las partes podrán ser tomadas en cuenta. En el presente caso no hay acuerdo entre las Partes sobre concesiones petroleras ${ }^{77}$.

El año 2007, en su sentencia del caso entre Nicaragua y Honduras, la Corte se refirió a estos acuerdos en el famoso párrafo 253, luego citado en otras sentencias de la CIJ y del Tribunal Internacional del Derecho del Mar. Se trata del párrafo en el que se apoya directamente la corte al decidir que existió un acuerdo tácito entre el Perú y Chile: «La evidencia de un acuerdo legal tácito debe ser convincente. El establecimiento de un límite marítimo permanente es una cuestión de grave importancia y el acuerdo no puede ser fácilmente presumido» ${ }^{78}$.

Posteriormente, el año 2008, en un caso sobre soberanía terrestre de ciertas islas entre Malasia y Singapur, la CIJ indicó que:

Toda transferencia de soberanía podría ser a través de acuerdo entre los dos Estados en cuestión. Dicho acuerdo podría tomar la forma de un tratado, como fue el Tratado Crawfurd de 1824 o el Acuerdo de 1927 referido previamente (párrafos 22, 28 y 102). El acuerdo en cambio podría ser tácito y surgir de la conducta de las Partes. El Derecho Internacional no impone en esta materia ninguna forma particular. En cambio, coloca el énfasis en las intenciones de las partes ${ }^{79}$.

Pero también señaló que:

Crucial para la evaluación de la Corte de la conducta de las Partes es la importancia central en el derecho y las relaciones internacionales de la soberanía estatal sobre el territorio y de la estabilidad y certidumbre de dicha soberanía. Debido a ello, toda transferencia de soberanía sobre territorio sobre la base de la conducta de las Partes, como se ha indicado

77 «Límite terrestre y marítimo (Camerún c. Nigeria; Guinea Ecuatorial interviniente). Sentencia». I.C.J. Reports, 2002, pp. 447-448, párrafo 304. Las cursivas son nuestras.

78 «Controversia territorial y marítima en el Mar Caribe (Nicaragua c. Honduras). Sentencia». I.C.J. Reports, 2007, p. 735 , párrafo 253; «Controversia territorial y marítima (Nicaragua c. Colombia). Sentencia». I.C.J. Reports, 2013, p. 705, párrafo 219; “Controversia concerniente a la delimitación de la frontera marítima entre Bangladesh y Myanmar en la Bahía de Bengala (Bangladesh/Myanmar)". Sentencia del 14 de marzo de 2002, p. 37, párrafo 95. Las cursivas son nuestras.

79 «Soberanía sobre Pedra Branca/Pulau Batu Puteh, Middle Rocks y South Ledge (Malasia/Singapur). Sentencia». I.C.J. Reports, 2008, p. 50, párrafo 120. Las cursivas son nuestras.

ANÁLISIS DE LOS

PRINCIPALES

ELEMENTOS DE

LA SENTENCIA

DE LA CORTE

INTERNACIONAL

DE JUSTICIA EN

EL CASO DE LA

CONTROVERSIA

MARÍTIMA (PERÚ C.

CHILE) A LA LUZ DE

LAS POSICIONES

DE LAS PARTES

ANALYSIS OF

THE MAIN

ELEMENTS OF THE

INTERNATIONAL

COURT OF JUSTICE

JUDGMENT IN THE

MARITIME DISPUTE

(PERU V. CHILE) IN

THE LIGHT OF THE

PARTIES POSITIONS 
anteriormente, debe ser manifestada claramente y sin ninguna duda sobre la conducta y los hechos relevantes ${ }^{80}$.

Así, para la Corte, en caso se discuta la existencia de un acuerdo entre Estados sobre soberanía territorial, no puede bastar la mera conducta de las partes para determinar si aceptaron o no un determinado acuerdo. Toda «transferencia de soberanía sobre territorio [...] debe ser manifestada claramente». Lo mismo se podría, razonablemente, afirmar sobre los espacios marítimos donde el Estado ejerce derechos de soberanía. No basta la mera conducta.

Respecto al caso entre el Perú y Chile, ya hemos indicado cómo la Corte otorga un rol central al texto (lo manifestado) del Convenio de 1954. La Corte considera que es el texto del Convenio el que «deja en claro», que resulta «decisivo» y que «refuerza el acuerdo tácito» ${ }^{81}$. La conducta, en realidad, resultó irrelevante en el caso para la determinación del acuerdo tácito, pues la Corte se basó exclusivamente en el texto del Convenio de 1954 que reconoce dicho acuerdo. El hecho de que el acuerdo tácito haya sido «manifestado» en 1954, en un tratado internacional formal, fue lo decisivo para la CIJ.

Queda claro entonces que el Convenio de 1954 no es el acuerdo tácito. Su texto simplemente lo reconoce. Igualmente, el acuerdo tácito no se identifica con las Proclamaciones de 1947 ni con la Declaración de Santiago de 1952. Esos son instrumentos expresos y ni las Proclamaciones son un acuerdo en su conjunto ni la Declaración estableció un límite marítimo entre el Perú y Chile. Más bien, como se ha explicado, el Perú hizo todo lo posible para evitar que un límite marítimo se derive de esos instrumentos, ya que los de 1947 y 1952 fueron concebidos por doscientas millas marinas y Chile sostuvo que el de 1954 también, sin éxito. Como es natural, lo anterior hace que surjan muchas dudas sobre cuándo, cómo, dónde, por qué extensión exacta, etcétera, se acordó tácitamente un límite marítimo, luego reconocido en 1954.

Respecto a qué es exactamente para el Derecho Internacional un acuerdo tácito, es decir, cuál es su naturaleza jurídica, no existe una respuesta cierta en este momento. La principal duda, discutida hoy en día en clases universitarias, eventos académicos y publicaciones especializadas, gira en torno a que la doctrina suele considerar que, para que haya un tratado internacional, la voluntad de las partes se debe manifestar ${ }^{82}$. Tanto lo escrito como lo verbal se manifiesta, así que pueden haber tratados escritos u orales, pero, itácitos? Si los acuerdos tácitos no son

80 lbídem, p. 51, párrafo 122. Las cursivas son nuestras.

81 "Controversia marítima (Perú c. Chile). Sentencia», párrafo 91.

82 REUTER, Paul. Introducción al derecho de los tratados. Segunda edición. México: Fondo de Cultura Económica, 2001, p. 47. 
tratados («si» colocado aquí como verdadera duda), entonces, ¿qué son? No se conoce a ciencia cierta.

Como hemos visto, en su sentencia del caso entre Malasia y Singapur, la Corte parece distinguir entre tratados y acuerdos tácitos, ambos diferentes tipos de acuerdos. A la vez, la Corte no duda de que existan los acuerdos tácitos como una figura específica del Derecho Internacional. De hecho, está convencida de ello. No solo la Corte ha empleado la figura en este caso y la ha contemplado en casos anteriores, sino que sus integrantes, en sus opiniones y declaraciones que acompañan el fallo, la comentan. Ninguno duda expresamente de que exista.

Skotnikov, en su declaración, deja constancia expresa de su acuerdo con la figura y su aplicación en el caso ${ }^{83}$. Owada precisa que «[1] os acuerdos tácitos que establecen cualquier tipo de límite internacional, sea terrestre o marítimo, son excepcionales por la simple razón de que cuando se trata de cuestiones de soberanía territorial, los Estados casi siempre son muy celosos» ${ }^{84}$. Guillaume, que al igual que Owada ha sido presidente de la Corte, escribió que la «Corte siempre ha reconocido la posibilidad de que Estados puedan celebrar esos acuerdos, pero esta es un área en la que se debe tener el mayor cuidado posible» ${ }^{85}$. SepúlvedaAmor aclara que

[c] omo una cuestión de principio, no me opongo a la proposición según la cual, si se dan las circunstancias apropiadas, un límite marítimo pueda estar basado en un acuerdo tácito. Similarmente, acepto que el hecho de que Chile deliberada y expresamente se abstuviera de invocar acuerdos tácitos como base de sus pedidos no impide que la Corte fundamente su decisión en esa base legal, ya que, para llegar a sus conclusiones, la Corte no está limitada por los argumentos presentados por cada Parte ${ }^{86}$.

ANÁLISIS DE LOS PRINCIPALES

ELEMENTOS DE

LA SENTENCIA

DE LA CORTE

INTERNACIONAL

DE JUSTICIA EN

EL CASO DE LA

CONTROVERSIA

MARÍTIMA (PERÚ C.

CHILE) A LA LUZ DE

LAS POSICIONES

DE LAS PARTES

ANALYSIS OF

THE MAIN

ELEMENTS OF THE

INTERNATIONAL

COURT OF JUSTICE

JUDGMENT IN THE

MARITIME DISPUTE

(PERU V. CHILE) IN

THE LIGHT OF THE

PARTIES POSITIONS

Igualmente, algunos de estos y otros jueces se pronunciaron específicamente sobre el alto estándar que la Corte ha establecido en el pasado para demostrar que existe un acuerdo tácito. Algunos consideran que no se llegó a este estándar en este caso ${ }^{87}$, otros que si $^{88}$. En resumen, todos confirman que los acuerdos tácitos existen como una figura específica del derecho internacional, aunque ninguno aclara si son o no tratados internacionales.

83 «Controversia marítima (Perú c. Chile). Declaración del Juez Skotnikov», párrafo 2.

84 «Controversia marítima (Perú c. Chile). Opinión separada del Juez Owada», párrafo 12.

85 «Controversia marítima (Perú c. Chile). Declaración del Juez ad hoc Guillaume», párrafo 9.

86 «Controversia marítima (Perú c. Chile). Declaración del Vicepresidente Sepúlveda-Amor», párrafo 3.

87 «Controversia marítima (Perú c. Chile). Opinión disidente de la Jueza Sebutinde», párrafos 3,6 y 15; "Controversia marítima (Perú c. Chile). Opinión separada del Juez Owada», párrafo 12.

88 «Controversia marítima (Perú c. Chile). Declaración de la Jueza Donoghue», primer párrafo. Sepúlveda-Amor considera que no se debe interpretar que la Corte se ha alejado del criterio previamente establecido del alto estándar de prueba. Ver «Controversia marítima (Perú c. Chile). Declaración del Vicepresidente Sepúlveda-Amor», párrafo 17. 


\section{IV.4.3. Extensión del límite marítimo derivado del acuerdo tácito}

La Corte se encontró en este caso en una situación muy especial. Por un lado, había descartado que el límite se derive de las Proclamaciones de 1947 o de la Declaración de 1952. Al no derivarse de ellas, no empleó esos instrumentos para justificar que el acuerdo tácito se extendía por doscientas millas marinas. Por otro lado, estaba convencida de que existió un acuerdo tácito, reconocido en el Convenio de 1954, pero el Convenio no especifica hasta dónde se aplica, solo que a partir de doce millas marinas de la costa. Por lo tanto, tenía que recurrir a otros medios para determinar la extensión del límite derivado del acuerdo tácito. Todo ello tiene una fundamentación lógica y jurídica que, salvo la figura del acuerdo tácito, fue presentada por el Perú y aceptada completamente por la Corte en su sentencia.

De paso, la Corte descartó por completo la tesis de Chile según la cual existió durante décadas un límite marítimo que se extendía por doscientas millas marinas y que ese Estado no tenía nada que negociar con el Perú o el Perú nada que reclamar ante la $\mathrm{CI}^{89}$. La Corte no encontró fundamento legal para esa afirmación. Como se indicó en la introducción de este artículo, también es posible hoy escuchar que, en realidad, fue la posición del Perú la que fue rechazada por la Corte, ya que la Corte encontró un acuerdo tácito. Pues bien, incluso en ese supuesto, que simplifica demasiado el caso tan complejo que se está comentando, la Corte no estuvo convencida de que el acuerdo tácito se proyecte por doscientas millas marinas de extensión. El modo en que llegó a esa decisión se ha explicado a lo largo de todo lo que va del texto. Fue una decisión basada en el derecho, contenida en diversos e intensos argumentos legales planteados por el Perú a lo largo de años que, finalmente, resultaron exitosos.

Volviendo a la posición especial en la que se encontró la Corte, la jueza Donoghue, en su declaración que acompaña al fallo, explica la dificultad de la CIJ para determinar el alcance y extensión del límite basado en un acuerdo tácito:

¿Cuál es, entonces, la extensión de este límite marítimo acordado tácitamente? Para responder esta pregunta la Corte, en efecto, llega a conclusiones sobre la sustancia de un acuerdo informal y no escrito. Sin embargo, debido a que las Partes no abordaron la existencia o términos de dicho tipo de acuerdo, no presentaron evidencia enfocada específicamente en la extensión del límite marítimo acordado tácitamente ${ }^{90}$.

89 Por ejemplo, el agente de Chile indicó ante la Corte el 6 de diciembre de 2012 que «la Declaración de Santiago estableció un completo e íntegro límite marítimo. No quedaron áreas para ser delimitadas. No quedaron reclamos a ser resueltos» (CR 2012/30, p. 19 (http://www.icj-cij.org/docket/ files/137/17210.pdf)).

90 «Controversia marítima (Perú c. Chile). Declaración de la Jueza Donoghue», segundo párrafo. 
¿Qué hizo, entonces, la Corte? Luego de establecer que el límite marítimo establecido mediante un acuerdo tácito abarca el agua, el lecho y el subsuelo submarinos (párrafos 100 a 102 del fallo), parte empleando dos argumentos concretos para determinar una distancia.

En primer lugar, opta por emplear información de la Organización de las Naciones Unidas para la Alimentación y la Agricultura (FAO), que se encuentra en los documentos del caso, para determinar hasta dónde pescaban y qué pescaban los dos Estados frente a sus costas (párrafos 104 a 107). Su intención es saber hasta dónde tenían los dos Estados interés en llegar a un acuerdo tácito. Concluye que las especies de la época «generalmente se encontraban dentro de un rango de 60 millas marinas de la costa» (párrafo 108). Expresamente, otorga importancia al hecho de que Ilo se encuentra a 120 kilómetros al norte del término del límite terrestre, mientras que Arica tan solo a 15. También se refiere a las embarcaciones que debían partir de esos puertos (mismo párrafo).

En segundo lugar, se refiere a la práctica estatal de la época en el ámbito general. En concreto, alude a múltiples declaraciones de Estados sobre zonas marítimas realizadas entre 1945 y 1950 y a la labor de la Comisión de Derecho Internacional de la ONU (112 a 117). Lamentablemente, no es específica en el contenido de esas declaraciones. Sin embargo, no duda en determinar que

sobre la base de las actividades pesqueras de las Partes en aquella época, las cuales se realizaban hasta una distancia de 60 millas marinas desde los puertos principales en el área, la práctica de otros Estados y el trabajo de la Comisión de Derecho Internacional sobre el Derecho del Mar, la Corte considera que la evidencia a su disposición no permite conchir que el límite marítimo acordado a_lo largo del paralelo se extienda más allá de 80 millas marinas desde su punto de inicio ${ }^{91}$.

De esa manera, la Corte llega a un límite máximo hacia el mar, un tope del paralelo en dirección al océano, en el que otorga expresamente un rol a los puertos principales de los dos Estados en el área (Ilo y Arica), pero todavía no ha determinado la extensión del límite acordado tácitamente. El juez Owada explica este cálculo en sus propios términos ${ }^{92}$. En los siguientes párrafos de su sentencia, la Corte analiza la práctica legislativa de las partes, un instrumento internacional de 1955, las actividades de patrullaje de los dos Estados, los documentos de 19681969 y las negociaciones con Bolivia de 1975-1976 (párrafos 119 a 133). Continúa con la posición de los dos Estados en la Tercera Conferencia de las Naciones Unidas sobre el Derecho del Mar, el Memorándum Bákula de 1986 y la práctica después de 1986 (párrafos 134 a 148). Concluye 
que ninguno de estos elementos aclara hasta dónde se extendió un límite marítimo. Chile argumentó a lo largo de todo el proceso que todos confirmaban la existencia de un límite por doscientas millas marinas ${ }^{93}$. La CIJ declara que, en base a toda la evidencia a su disposición, el límite se extendió por ochenta millas marinas (párrafo 151).

La Corte hizo un esfuerzo por explicar cómo determinó que el límite marítimo acordado tácitamente se extendió por ochenta millas marinas. Dedica más de cincuenta párrafos a esa determinación, más de la cuarta parte de la sentencia. Sin embargo, su explicación pudo haber sido más precisa. La CIJ descartó que el límite se extienda hasta doscientas millas marinas aceptando argumentos planteados por el Perú, determinó que el acuerdo tácito debía ir más allá de doce millas sobre la base del texto del Convenio de 1954 y, luego, con la información que tenía a su disposición, pero sin que las partes hayan fundamentado la extensión de un acuerdo tácito de no menos de doce millas pero que no llegue a doscientas millas marinas, tomó su propia decisión.

\section{EL PUNTO DE INICIO DEL LÍMITE MARÍTIMO}

El Perú, al haber presentado a la Corte la posición que Chile y Perú nunca acordaron un límite marítimo, lógicamente, planteó que el límite marítimo se inicie en el lugar donde se inicia la frontera terrestre, es decir, el punto Concordia, tal como está definido en el artículo segundo del Tratado de Lima de 1929. Como se sabe, este aspecto del primer pedido del Perú a la Corte no prosperó. La Corte determinó que el punto de inicio para el límite marítimo es «la intersección del paralelo de latitud que pasa por el Hito 1 con la línea de bajamar» (párrafo 176). La Corte aborda lo relacionado con el punto de inicio del límite en los párrafos 152 a 176 de su fallo.

Para diferenciar bien entre el punto Concordia y el Hito Número 1 es necesario referirnos brevemente al Tratado de Lima de 1929, donde se acordó el primero, y al proceso de demarcación de 1929-1930, en el que se acordó dónde se colocaría el segundo, el Hito, que es y siempre ha sido distinto al punto Concordia. En primer lugar, el Tratado de Lima de 1929 estableció el límite terrestre entre el Perú y Chile, el cual no había sido establecido luego de la Guerra del Pacífico. Su artículo segundo señala que «[1]a línea divisoria entre dichas dos partes [Tacna y Arica] y, en consecuencia, la frontera entre los territorios del Perú y de Chile, partirá de un punto de la costa que se denominará "Concordia", distante diez kilómetros al norte del puente del Río Lluta». 
En tal sentido, el Tratado de Lima estableció el límite terrestre, delimitó la frontera. Para señalizar la frontera, lo cual normalmente se conoce como demarcación, se constituyó una Comisión Mixta Demarcadora de Límites Peruano-Chilena. En el seno de esa Comisión se produjo un desacuerdo entre el miembro peruano y el miembro chileno en relación con el trayecto inicial del límite terrestre. El desacuerdo fue elevado a los gobiernos de los dos Estados y fue resuelto por ellos de común acuerdo. Como consecuencia de ese acuerdo, los dos Estados enviaron instrucciones idénticas a sus miembros en la Comisión Mixta Demarcadora $^{94}$. La instrucción peruana señala lo siguiente:

Se medirán diez kilómetros desde el primer puente del ferrocarril de Arica a La Paz sobre el río Lluta, en dirección hacia el Norte, en la Pampa de Escritos, y se trazará, hacia el poniente, un arco de diez kilómetros de radio, cuyo centro estará en el indicado puente y que vaya a intersectar la orilla del mar, de modo que, cualquier punto del arco, diste 10 kilómetros del referido puente del ferrocarril de Arica a La Paz sobre el río Lluta. Este punto de intersección del arco trazado con la orilla del mar, será el inicial de la línea divisoria entre el Perú y Chile. Se colocará un hito en cualquier punto del arco, lo más próximo al mar posible, donde quede a cubierto de ser destruido por las aguas del océano ${ }^{95}$.

Las instrucciones idénticas de 1930 no dejan duda alguna acerca de la diferencia entre el punto Concordia, el inicial del límite terrestre, y el primer hito, conocido como Hito Número 1. La evidencia documental contemporánea presentada por el Perú ante la Corte, incluyendo la Cartografía chilena de esa época, confirma también, completamente, la diferencia entre el punto Concordia y el Hito Número $1^{96}$. El Hito fue colocado a una distancia prudente del punto Concordia y, ya que el arco donde se colocó el Hito sigue una dirección noreste desde el punto Concordia, el Hito se encuentra más al norte del punto de inicio del límite terrestre.

Por otro lado, resulta importante recordar que el caso planteado ante la Corte fue un caso estrictamente de delimitación marítima. Ni el Perú ni Chile solicitaron a la Corte que se pronuncie sobre asunto terrestre alguno (ver apartado 2). Recordemos también que la Corte no es competente para resolver casos que «se hallen regidos por acuerdos o tratados en vigencia en la fecha de la celebración del presente Pacto», como señala el Artículo VI del Pacto de Bogotá de 1948. El límite terrestre entre el Perú y Chile fue acordado en un tratado internacional en 1929. Por lo tanto, la Corte no es competente para abordar algún asunto relacionado al límite terrestre entre el Perú y Chile. 
Entonces, en el caso de delimitación marítima ante la CIJ, el Perú solo solicitó que el límite marítimo se inicie ahí donde se inicia el límite terrestre, sobre la base de que no existía límite marítimo acordado entre el Perú y Chile ni punto de inicio de un límite marítimo acordado. Para tal efecto, no se pidió que la Corte defina ni altere el límite terrestre, solo que tome nota de lo que establece el Tratado de Lima de 1929 y del proceso de demarcación que culminó en 1930. La presentación de la documentación de la época, que claramente distingue entre el punto Concordia y el Hito, sirvió también otro propósito. En su Contramemoria, Chile afirmó que «el límite terrestre ha sido completamente determinado y demarcado, y el Hito No. 1 es el término hacia el mar del límite terrestre como ha sido determinado por acuerdo de las Partes» ${ }^{97}$. Esa afirmación no se repitió luego de que el Perú demostró en su Réplica que el Hito no se debe confundir con el punto Concordia ${ }^{98}$.

Finalmente, la Corte decidió que hubo un límite marítimo acordado tácitamente y también determinó que en documentos de 1968 y 1969 las partes acordaron un punto de inicio concreto para ese límite marítimo. En efecto, para la Corte, «ambas Partes se refirieron claramente a su entendimiento de que la tarea que iban a realizar conjuntamente» en base a los mencionados documentos sobre la colocación de faros en la costa de 1968 y 1969 «involucra la materialización del paralelo de la existente frontera marítima, entendido tal paralelo como el que pasa por el Hito No. $1 »^{99}$.

Así, el límite terrestre se inicia en el punto Concordia, el límite marítimo tiene su propio punto de inicio en «la intersección del paralelo de latitud que pasa por el Hito No. 1 con la línea de bajamar» y el Hito Número 1 no se identifica con el punto Concordia ni es el punto de inicio del límite marítimo. Se trata de tres cosas distintas. El juez Guillaume en su declaración confirma que «la costa entre el punto de inicio del límite marítimo y el Punto Concordia se encuentra bajo la soberanía del Perú, mientras que el mar pertenece a Chile. Sin embargo, esta situación no carece de precedentes» ${ }^{100}$.

A pesar de la decisión de la Corte sobre el punto de inicio del límite marítimo, la sentencia de la Corte en su párrafo 175 señala lo siguiente:

A la Corte no se le ha pedido que tome posición sobre la ubicación del Punto Concordia, donde la frontera terrestre entre las Partes se inicia. Toma nota de que puede ser posible que el mencionado punto

$97 \mathrm{CMC}$, párrafo 2.16

$98 \mathrm{RP}$, párrafos 2.1 a 2.77 .

99 «Controversia marítima (Perú c. Chile). Sentencia», párrafo 169. Sobre los documentos de 1968 y 1969, ver MP, párrafos 6.33-6.46; RP, párrafos 2.1 a 2.77; CR 2012/29, pp. 34-44 (http://www.icj-cij. org/docket/files/137/17208.pdf).

100 «Controversia marítima (Perú c. Chile). Declaración del Juez ad hoc Guillaume», párrafo 15. 
no coincida con el punto de inicio del límite marítimo, tal como acaba de ser definido [en párrafos anteriores]. La Corte observa, sin embargo, que dicha situación sería la consecuencia de acuerdos alcanzados entre las Partes.

Por su parte, el párrafo 153 confirma que «[a]mbas partes están de acuerdo en que el límite terrestre entre ellas fue resuelto y delimitado hace más de 80 años de acuerdo con el Artículo 2 del Tratado de Lima de $1929 »$. Ese es el tratado que define el límite terrestre y al que uno se debe de remitir sobre esa materia.

\section{EL TRAZADO DEL LÍMITE MARÍTIMO MÁS ALLÁ DEL PUNTO DONDE TERMINA EL PARALELO}

El Perú solicitó a la Corte, a lo largo de sus alegatos escritos y orales, que establezca un límite marítimo conforme a la costumbre internacional, según la cual el objetivo de la delimitación marítima debe ser llegar a una solución equitativa. Propuso que la Corte emplee para ello el método de tres pasos que ha establecido en su jurisprudencia con tal propósito $^{101}$. Por su parte, la Corte afirmó en el párrafo 182 de su fallo que «Chile no presentó argumentos sobre este tema. Su posición a lo largo de todo el proceso fue que las Partes ya habían delimitado la totalidad del área en disputa, mediante acuerdo, en 1952, y que, de acuerdo con ello, la Corte no debía realizar ninguna delimitación marítima» ${ }^{102}$.

En su discurso ante la Comisión de Derecho Internacional de la ONU el pasado 22 de julio de 2014, el presidente de la Corte relató cómo procedió la CIJ para establecer el límite marítimo entre el Perú y Chile, lo cual efectuó entre los párrafos 177 y 195 de su decisión:

[Respecto] a la determinación del curso del límite marítimo no definido a partir del punto final de la frontera marítima acordada, la Corte procedió sobre la base de los Artículos 74(1) y 83(1) de la CONVEMAR, los cuales, como ha confirmado la jurisprudencia de la Corte, reflejan el derecho internacional consuetudinario. [...] [R]ecordando que en la práctica algunas delimitaciones han sido realizadas desde puntos de inicio no localizados en la línea de bajamar, sino mar adentro. [...] En contraste, sin embargo, la Corte subrayó que en la Controversia Marítima entre el Perú y Chile, «[l]a situación que la Corte enfrenta [fue] ... inusual ya que el punto de inicio de la delimitación en este caso [estaba] mucho más alejado de la costa: 80 millas marinas desde el punto más cercano en la costa chilena y unas 45 millas marinas desde el punto más cercano de la costa peruana».

ANÁLISIS DE LOS

PRINCIPALES

ELEMENTOS DE

LA SENTENCIA

DE LA CORTE

INTERNACIONAL

DE JUSTICIA EN

EL CASO DE LA

CONTROVERSIA

MARÍTIMA (PERÚ C.

CHILE) A LA LUZ DE

LAS POSICIONES

DE LAS PARTES

ANALYSIS OF

THE MAIN

ELEMENTS OF THE

INTERNATIONAL

COURT OF JUSTICE

JUDGMENT IN THE

MARITIME DISPUTE

(PERU V. CHILE) IN

THE LIGHT OF THE

PARTIES POSITIONS 
En todo caso, la Corte luego procedió a aplicar su usual metodología de tres pasos para delimitar el área de derechos que se superponen situados más allá del punto terminal del límite marítimo acordado; primero, al trazar una línea equidistante provisional, luego dedicándose a la evaluación de cualquier circunstancia relevante que requiriese el ajuste de la línea y, finalmente, aplicando la prueba de «desproporcionalidad», todo con el objetivo de alcanzar una solución equitativa. En este caso particular, la Corte anotó que no se presentan en el registro ante ella circunstancias relevantes y, consecuentemente, no hubo base para ajustar la línea equidistante provisional. Similarmente, debido a las circunstancias inusuales del caso ante ella, la Corte concluyó que no era evidente ninguna desproporción importante, del tipo que ponga en cuestión la naturaleza equitativa de la línea provisional equidistante ${ }^{103}$.

Es de notar que, técnicamente, la Corte no efectuó la prueba de desproporcionalidad que normalmente realiza como tercer paso en la delimitación marítima, ya que ello involucra calcular 1) las costas relevantes y 2) cómo divide el límite la zona de superposición, lo cual no era posible por lo lejos de la costa que se iniciaba el límite marítimo. Así, en el párrafo 193 efectuó una simple «evaluación general de la desproporcionalidad».

Cabe resaltar, asimismo, que la Corte no otorgó ningún valor para la delimitación marítima a la supuesta práctica alegada por Chile de décadas de empleo de un paralelo por doscientas millas marinas de extensión, confirmando lo que el Perú argumentó al respecto y la jurisprudencia de la CIJ en la materia ${ }^{104}$.

\section{VII.LOS DERECHOS DEL PERÚ EN EL ÁREA UBICADA DENTRO DE LAS DOSCIENTAS MILLAS MARINAS DE SUS LÍNEAS DE BASE PERO MÁS ALLÁ DE LAS DOSCIENTAS MILLAS MARINAS DE LAS LIINEAS DE BASE DE CHILE}

Ya en su solicitud de 2008, el Perú indicó a la Corte que «[1]a controversia entre el Perú y Chile también involucra el reconocimiento a favor del Perú de una extensa zona marítima ubicada dentro de las 200 millas marinas de la costa del Perú, y por lo tanto correspondiente al Perú, pero que Chile considera parte de alta mar» ${ }^{105}$. Añadió que «[b]ajo principios y normas bien establecidos del derecho internacional, el Perú tiene derecho a contar con áreas marítimas dentro de las 200 millas marinas

103 «Discurso de S.E. Peter Tomka, Presidente de la Corte Internacional de Justicia, en la Sexagésima Sexta Sesión de la Comisión de Derecho Internacional», 22 de julio de 2014, p. 5.

104 «Controversia territorial y marítima (Nicaragua c. Colombia)». I.C.J. Reports, 2012, pp. 704-705, párrafos 217-220.

105 «Controversia marítima (Perú c. Chile). Solicitud», p. 2, párrafo 1. Las cursivas son nuestras. 
de sus líneas de base y más allá de las 200 millas marinas de las líneas de base de Chile»; por ello, «las afirmaciones de Chile en sentido contrario carecen de todo mérito» ${ }^{106}$.

En efecto, como el Perú indicó en su solicitud en esta materia, existía una controversia jurídica con Chile, controversia entendida como «un desacuerdo sobre un punto de derecho», es decir, «un conflicto de puntos de vista legales o de intereses entre dos personas ${ }^{107}$. Los puntos de vista legales opuestos consistían en que, para el Perú, esa zona correspondía indudablemente a ese Estado, mientras que, para Chile, era parte de alta mar. El régimen jurídico de la alta mar forma parte de la costumbre internacional y se encuentra reflejado en el texto de la Convención de las Naciones Unidas sobre el Derecho del Mar (CONVEMAR) ${ }^{108}$. Por lo tanto, la calificación de Chile de esa zona como alta mar implicaba que ella está «abierta a todos los Estados», los cuales pueden ejercer en ella libertad de pesca ${ }^{109}$, y que el Perú no podía «pretender legítimamente someter cualquier parte de ella a su soberanía ${ }^{110}$.

Al existir una controversia jurídica sobre esta cuestión, el Perú actuó como establece el derecho internacional, es decir, buscó solucionarla por un medio pacífico según los artículos 2.3 y 33 de la Carta de la ONU. En tal sentido, estuvo plenamente justificado solicitar a la Corte que se pronuncie sobre los derechos del Perú en esa zona.

Para fundamentar la existencia de una controversia sobre esta zona que, para propósitos únicamente prácticos, el Perú llamó en el proceso «triángulo exterior» ${ }^{111}$, en la Memoria se indicó que la ley número 19.080 de Chile del 28 de agosto de 1991 calificó esta área como parte del «mar presencial» de Chile, el cual, a su vez, estaba definido como «parte de la alta mar» en esa ley ${ }^{112}$. Para evitar confusiones, el Perú precisó que

[n]o es la intención del Perú ofrecer visiones generales sobre la legalidad de las reclamaciones de Chile sobre un «Mar Presencial» o la compatibilidad de este muy inusual concepto con el moderno Derecho del Mar [...]. Para los propósitos presentes basta notar que incluso aunque el área es descrita prudentemente como una «porción de la alta mar» en varias regulaciones chilenas, resulta claro que esta zona definida unilateralmente invade la zona marítima exclusiva del Perú y

106 Ibídem, p. 6, párrafo 12.

107 «Asunto de las Concesiones Mavrommantis en Palestina». C.P.J.I. Serie A, número 2, 30 de agosto de 1924, p. 11.

108 CHURCHILL, Robin y Vaughan LOWE. The law of the sea. Tercera edición. Manchester: Manchester University Press, 1999, pp. 203-205.

109 CONVEMAR, articulo 87.

110 Ibídem, artículo 89.

$111 \mathrm{MP}$, párrafo 7.6 .

112 Ibídem, párrafo 7.10 .

ANÁLISIS DE LOS PRINCIPALES

ELEMENTOS DE

LA SENTENCIA

DE LA CORTE

INTERNACIONAL

DE JUSTICIA EN

EL CASO DE LA

CONTROVERSIA

MARÍTIMA (PERÚ C.

CHILE) A LA LUZ DE

LAS POSICIONES

DE LAS PARTES

ANALYSIS OF

THE MAIN

ELEMENTS OF THE

INTERNATIONAL

COURT OF JUSTICE

JUDGMENT IN THE

MARITIME DISPUTE

(PERU V. CHILE) IN

THE LIGHT OF THE

PARTIES POSITIONS 
es, por tanto, claramente incompatible con los derechos soberanos del Perú hasta una distancia de 200 millas marinas de sus líneas de base ${ }^{113}$.

La respuesta de Chile en su Contramemoria y durante el resto del proceso resultó sorprendente: se opuso totalmente a que la Corte reconozca los derechos del Perú en dicha zona. La Corte, en su sentencia, no recoge bien el argumento planteado por Chile durante el proceso. En líneas generales, solo dedicó tres párrafos de su fallo a toda la compleja y extensa discusión de las partes sobre esta materia (párrafos 187 a 189), cuando las partes habían abordado el tema ampliamente en cada alegato escrito que presentaron y en las dos semanas de las audiencias orales de manera mucho más completa al modo como la Corte se refiere. Para la Corte, «Chile en respuesta [al Perú] sostiene que la Declaración de Santiago establece un límite lateral único para todas las áreas marítima de sus Estados partes sean reales o potenciales, invocando la referencia en el párrafo II de la Declaración a "hasta una distancia mínima de 200 millas marinas"» 114 .

Pero Chile no fundamenta su posición solo en el texto del punto II de la Declaración, sino que se remitió concretamente a las minutas de la Segunda Sesión de la Comisión Jurídica de la Conferencia de Santiago de 1952. En dicha sesión, los representantes de Perú, Chile y Ecuador dejaron constancia de que cualquiera de sus Estados «soberanamente, pueden [sic] en cualquier tiempo que lo estime conveniente o necesario ampliar su zona jurisdiccional más allá de las doscientas millas en la extensión que juzgue adecuada sin necesidad de solicitar la venia o el acuerdo de los otros países signatarios» ${ }^{115}$.

Chile complementó su argumento afirmando que la Declaración estableció límites marítimos a través de paralelos de latitud por doscientas millas marinas, los cuales debían seguir empleándose en caso cualquiera de los tres Estados extienda su zona marítima unilateralmente ${ }^{116}$. Perú contestó decididamente todos estos argumentos de Chile y la Corte en su sentencia (aunque no en los breves tres párrafos que dedicó a todo este debate) negó completamente los dos fundamentos de la postura chilena en la materia. Es decir, negó que la Declaración de Santiago haya establecido límite marítimo alguno y negó que haya existido antes del fallo un límite en el paralelo por doscientas millas marinas que pueda continuar aplicándose incluso más allá de esas doscientas millas marinas.

Por otro lado, el Perú en su Réplica indicó que el «único argumento posible a favor de la posición de Chile hubiera sido una renuncia expresa 
por parte del Perú» a esa zona ${ }^{117}$. No existió, por supuesto, renuncia alguna posterior a la Declaración de Santiago y, en todo caso, Chile no argumentó que haya habido una renuncia posterior, sino que en la propia Declaración, interpretada según las minutas de la mencionada reunión, el Perú se habría autolimitado a reclamar zona alguna al sur del paralelo. Así, según Chile, el paralelo se extendería ad infinitum.

Alain Pellet, en nombre del Perú, ahondó durante las audiencias orales, el 11 de diciembre de 2012, sobre esa absurda posibilidad. En efecto, la Declaración garantiza a cada Estado una zona de, por lo menos, doscientas millas marinas. El antes llamado «triángulo exterior» se ubica dentro de la zona de doscientas millas marinas del Perú pero, como señaló Pellet, Chile pretendía argumentar que «el Perú habría renunciado a una parte muy importante de sus derechos en el momento mismo en el que los proclamaba ante el mundo junto con sus socios y en el mismo instrumento en el cual los proclamaba» ${ }^{118}$.

La Corte tampoco mencionó expresamente esos argumentos del Perú. Nótese en especial qué inadecuado resulta el párrafo 188 del fallo para explicar las posiciones de las partes sobre toda esta materia. Igualmente, la explicación que da la Corte no es completa. Simplemente indicó que «ya que la Corte ha decidido que procederá con la delimitación de los derechos marítimos que se superponen de las partes mediante una línea equidistante, el segundo pedido del Perú se ha vuelto académico [moot] y la Corte no necesita pronunciarse sobre él» ${ }^{119}$.

¿Cómo interpretar, entonces, la negativa de la Corte de pronunciarse sobre el segundo pedido del Perú? En primer lugar, teniendo en cuenta que la Corte no dio valor alguno a los argumentos de Chile para negar los derechos del Perú. Por el contrario, al encontrar que no hubo ningún límite pactado en 1952 que alcance doscientas millas marinas y que pueda ser extendido incluso más allá, rechazó indirectamente (pero de plano) toda la argumentación de Chile para negar los derechos del Perú en la zona bajo análisis. Los argumentos de Chile no tuvieron ningún efecto en este tema.

Por otro lado, dos jueces se pronunciaron en el mismo sentido en sus declaraciones y opiniones que acompañan la sentencia. Ninguno se pronunció en sentido contrario. El juez Tomka, quien, sin embargo, favoreció un límite en el paralelo geográfico por doscientas millas marinas, señaló lo siguiente:

estoy de acuerdo con la conclusión de la Corte de que no es necesario que se pronuncie sobre el pedido del Perú sobre el llamado «triángulo

ANÁLISIS DE LOS PRINCIPALES

ELEMENTOS DE

LA SENTENCIA

DE LA CORTE

INTERNACIONAL

DE JUSTICIA EN

EL CASO DE LA

CONTROVERSIA

MARÍTIMA (PERÚ C.

CHILE) A LA LUZ DE

LAS POSICIONES

DE LAS PARTES

ANALYSIS OF

THE MAIN

ELEMENTS OF THE

INTERNATIONAL

COURT OF JUSTICE

JUDGMENT IN THE

MARITIME DISPUTE

(PERU V. CHILE) IN

THE LIGHT OF THE

PARTIES POSITIONS 
exterior». Los derechos del Perú sobre ese espacio marítimo han sido reconocidos en la Sentencia por la forma en la que la Corte ha trazado el límite marítimo. El triángulo exterior es parte de la zona económica exclusiva y plataforma continental del Perú ${ }^{120}$.

El juez Guillaume coincidió, afirmando lo siguiente: «[y]o también estoy de acuerdo con el razonamiento de la Corte y con el resultado respecto al triángulo exterior, sobre el cual el Perú está facultado a ejercer derechos soberanos bajo las condiciones establecidas por el derecho internacional» ${ }^{121}$.

\section{EL PÁRRAFO 178 Y LA INVOCACIÓN DEL PERÚ A LA COSTUMBRE INTERNACIONAL EN EL CASO}

A lo largo de todo el procedimiento ante la Corte, Chile cuestionó duramente la naturaleza jurídica del dominio marítimo del Perú y las intenciones del Perú al presentar el caso ante la CIJ. En su Contramemoria, Chile sugirió que el Perú cuenta con un mar territorial de doscientas millas marinas de extensión (párrafos 2.166 a 2.176), lo cual es incorrecto, y que «[e]sta es la zona que el Perú pretende que la Corte delimite y expanda para absorber el área de alta mar» (párrafo 2.173), que es como llamaba al «triángulo exterior». De esa manera insinuaba que 1) el Perú cuenta con una zona contraria al derecho internacional (mar territorial de doscientas millas marinas) y 2) que el Perú pretendía indebidamente que la Corte consagre y expanda esa zona ilícita.

En su Dúplica, Chile dedicó toda una sección del capítulo 7 (párrafos 7.38 a 7.50) a este tema. Afirmó que el dominio marítimo del Perú es «una zona de doscientas millas marinas indiferenciada equivalente a un mar territorial» (párrafo 7.38). También que «Perú busca evitar las obvias dificultades de solicitar a la Corte que expanda una zona marítima que ni está reconocida ni cumple con el derecho internacional consuetudinario» (párrafo 7.42). Insistió indicando que «[e]l "dominio marítimo" del Perú no es conforme con la costumbre internacional. La Corte no debe autorizar el intento del Perú» de expandirlo, pues «[s]ería en detrimento no solo de Chile, sino de la comunidad internacional» (párrafo 7.49).

Durante las audiencias orales, el 6 de diciembre de 2012, el agente de Chile ante la Corte señaló que «Chile ratificó la CONVEMAR y adaptó su legislación interna a ella. El Perú no hizo ninguna de las dos cosas. El Perú argumenta que la CONVEMAR es la base para alterar y 
renegociar un límite marítimo acordado, sin embargo, no está dispuesto a ratificarla» ${ }^{122}$. Esa afirmación encierra un doble error: 1) que el Perú fundamentó su caso en la Convención del Mar, lo cual no es cierto, pues, como se verá a continuación, el caso se fundamentó exclusivamente en la costumbre internacional; y 2) que se propuso alterar un límite marítimo acordado, cuando el pedido del Perú fue que la Corte lo establezca ex novo. La sentencia de la CIJ, por cierto, no altera tampoco ningún límite marítimo acordado, ya que para la Corte existió un límite por ochenta millas marinas, pero no más allá de estas, por lo que procedió a delimitar lo que no existía legalmente.

Por otro lado, la sugerencia de que el Perú no está dispuesto a aprobar la Convención del Mar va de la mano con el argumento ampliamente desarrollado por Chile previamente en el sentido de que el Perú incumple el derecho del mar contemporáneo. Debido a todo ello, en el caso resultó central precisar cuál es la base legal del derecho que el Perú pidió a la Corte que aplique y aclarar que el Perú no solicita nada contrario al derecho internacional.

Por limitaciones de espacio no es posible abordar en este artículo las razones por las cuales el dominio marítimo del Perú no equivale a un mar territorial de doscientas millas marinas de extensión, sino que siempre ha consistido, más bien, en una zona marítima distinta al mar territorial ${ }^{123}$. Ella influyó en la formación de las actuales zonas marítimas que los Estados gozan hasta doscientas millas marinas de sus costas y permite que se aplique en su interior precisamente el régimen legal internacional de los espacios marítimos existentes el día de hoy en virtud de la costumbre internacional.

La Corte tiene como función «decidir conforme al derecho internacional las controversias que le sean sometidas» (artículo 38.1 de su Estatuto). Desde la solicitud de 2008 y a lo largo de todos los argumentos escritos y orales, el Perú no hizo otra cosa que invocar y pedirle a la Corte que aplique la costumbre internacional, la cual es clara al señalar cómo se delimita cada zona marítima ${ }^{124}$. Si no hubiese sido posible invocar la costumbre, al no ser el Perú parte de la Convención del Mar de 1982, el Perú no hubiera tenido una base legal para plantear su caso.

122 CR 2012/30, p. 17, párrafo 5.2 .

123 Ver FerRero CostA, Eduardo. El nuevo derecho del mar. El Perú y las 200 Millas. Lima: Fondo Editorial de la Pontificia Universidad Católica del Perú, 1979, pp. 54, 71 y 454; BÁKULA, Juan Miguel. El dominio marítimo del Perú. Lima: Fundación Bustamante de la Fuente, 1985, pp. 153, 249 y 339; Agüero Colunga, Marisol. Consideraciones para la delimitación marítima del Perú. Lima: Fondo Editorial del Congreso del Perú, 2001, pp. 251-260; RuBIO CoRREA, Patricio. «Compatibilidad entre la Convención del Mar de 1982 y la Constitución Política del Perú». En Sandra NamiHAS (ed.). Derecho del mar. Análisis de la Convención de 1982. Lima: Fondo Editorial de la Pontificia Universidad Católica del Perú, 2001, pp. 263-285; GaRCía Belaunde, Domingo. Constitución y dominio marítimo. Lima: Instituto Iberoamericano de Derecho Constitucional, 2002, pp. 15-39.

124 MP, capítulo Vl; RP, capítulo V; CR 2012/27, pp. 34-45.

ANÁLISIS DE LOS PRINCIPALES

ELEMENTOS DE

LA SENTENCIA

DE LA CORTE

INTERNACIONAL

DE JUSTICIA EN

EL CASO DE LA

CONTROVERSIA

MARÍTIMA (PERÚ C.

CHILE) A LA LUZ DE

LAS POSICIONES

DE LAS PARTES

ANALYSIS OF

THE MAIN

ELEMENTS OF THE

INTERNATIONAL

COURT OF JUSTICE

JUDGMENT IN THE

MARITIME DISPUTE

(PERU V. CHILE) IN

THE LIGHT OF THE

PARTIES POSITIONS 
En tal sentido, durante las audiencias orales, el agente del Perú hizo declaraciones ante la Corte en nombre del Gobierno del Perú que la CIJ recogió parcialmente en el párrafo 178 de su sentencia. Dicho párrafo señala que

[m] ientras que Chile ha firmado y ratificado la CONVEMAR, el Perú no es parte de dicho instrumento. Ambas Partes reclaman derechos marítimos de 200 millas marinas. Ninguna de las dos Partes reclama una plataforma continental extendida en el área que concierne a este caso. La reclamación de Chile consiste en un mar territorial de 12 millas marinas y en una zona económica exclusiva y plataforma continental que se extiende hasta 200 millas marinas de la costa. El Perú reclama un «dominio marítimo» de 200 millas marinas. El Agente del Perú formalmente declaró en nombre de su Gobierno que «[e]l término "dominio marítimo" empleado en la Constitución [del Perú] es aplicado de manera consistente con las zonas marítimas señaladas en la Convención de 1982». La Corte toma nota de esta declaración, la cual expresa un compromiso formal del Perú.

Este fue el único párrafo del fallo que la Corte dedicó, aunque de manera indirecta, a los serios y repetidos cuestionamientos que Chile planteó sobre la naturaleza jurídica del dominio marítimo del Perú. Por lo tanto, toda esa línea argumentativa de Chile fue rechazada por la Corte.

Por otro lado, en el párrafo 178 del fallo la expresión «compromiso» formal (en inglés formal undertaking, en francés engagement formel) empleada por la Corte nos deriva a las sentencias de la CIJ de 1974 sobre los ensayos nucleares franceses. En dichos fallos, se hace referencia a ciertas declaraciones unilaterales capaces de generar obligaciones legales a los Estados también como «compromisos» legales ${ }^{125}$. La Corte, entonces, parece entender que el Perú realizó una de las referidas declaraciones unilaterales.

¿En qué consistiría esta declaración? Pues la Comisión de Derecho Internacional (CDI) de la ONU, en su Quincuagésima Octava Sesión el año 2006, aprobó los Principios Rectores Aplicables a las Declaraciones Unilaterales de los Estados Capaces de Crear Obligaciones Jurídicas, con Comentarios ${ }^{126}$. Tomando como base diversos casos de la jurisprudencia internacional, el principio rector número 7 de la $\mathrm{CDI}$ sobre esta materia señala que «[e]n caso de duda sobre el alcance de las obligaciones resultantes de una declaración de este tipo, tales obligaciones deben

125 «Ensayos Nucleares (Australia c. Francia). Sentencia». I.C.J. Reports, 1974, p. 267, párrafo 43; «Ensayos Nucleares (Nueva Zelanda c. Francia). Sentencia». I.C.J. Reports, 1974, p. 472, párrafo 46.

126 Ver: http://legal.un.org/ilc/texts/instruments/english/commentaries/9_9_2006.pdf. La Asamblea General de la ONU, en su resolución 61/34 del 4 de diciembre de 2006, tomó nota de dichos Principios Rectores y recomendó su difusión. 
ser interpretadas de manera restrictiva». Añade que «[a]l interpretar el contenido de tales declaraciones, se debe otorgar peso primero y sobre todo al texto de la declaración, junto con el contexto y las circunstancias en las que fueron formulada».

Debemos acudir, entonces, principalmente, al texto de las declaraciones del embajador Wagner ante la Corte para poder interpretarlas. Ello resulta importante, más aún, porque la Corte solo cita en el párrafo 178 una parte (corta) de dichas declaraciones en nombre del Gobierno del Perú. El embajador Wagner se refirió a este tema en sus discursos inicial y final durante las audiencias orales en diciembre de 2012. El 3 de diciembre, señaló lo siguiente:

Sr. Presidente, en nombre del Gobierno del Perú, deseo formalmente dejar constancia del compromiso del Perú con el moderno derecho del mar como se encuentra reflejado en la Convención de las Naciones Unidas sobre el Derecho del Mar de 1982. La Constitución del Perú de 1993, su derecho interno y la práctica del Perú se encuentran en plena conformidad con el derecho del mar contemporáneo. El término «dominio marítimo» empleado en nuestra constitución es aplicado de manera consistente con las zonas marítimas señaladas en la Convención de 1982; la Constitución se refiere expresamente a la libertad de comunicación internacional.

En resumen, el Perú acepta y aplica las normas del derecho internacional del mar consuetudinario como están reflejadas en la Convención.

La simple realidad es que el Perú no solicita nada más que lo que corresponde a todo Estado ribereño bajo el derecho internacional ${ }^{127}$.

Igualmente, en su discurso final a la Corte el 11 de diciembre de 2012, el agente del Perú indicó lo siguiente:

Finalmente, Sr. Presidente, quisiera reiterar, en nombre de mi Gobierno, el compromiso del Perú con el moderno derecho del mar como está reflejado en la Convención de las Naciones Unidas sobre el Derecho del Mar. [...] A pesar de lo que algunos abogados de Chile han expresado en el curso de estas audiencias, el término «dominio marítimo» empleado en nuestra Constitución es aplicado de una manera consistente con las zonas marítimas señaladas en la Convención de 1982. En resumen, el Perú acepta y aplica las normas del derecho internacional del mar consuetudinario, como están reflejadas en la Convención ${ }^{128}$.

En vista de lo anterior, el «compromiso formal» que la CIJ atribuye al Perú no se refiere a otra cosa que a que el Perú acepta y respeta la costumbre

ANÁLISIS DE LOS PRINCIPALES ELEMENTOS DE

LA SENTENCIA DE LA CORTE INTERNACIONAL DE JUSTICIA EN

EL CASO DE LA CONTROVERSIA MARÍTIMA (PERÚ C. CHILE) A LA LUZ DE LAS POSICIONES DE LAS PARTES

ANALYSIS OF

THE MAIN

ELEMENTS OF THE INTERNATIONAL COURT OF JUSTICE JUDGMENT IN THE MARITIME DISPUTE (PERU V. CHILE) IN THE LIGHT OF THE PARTIES POSITIONS 
internacional. El embajador Wagner no señaló nada más que eso. A pesar de que podemos estar de acuerdo con (y desear que) un día el Perú sea parte de la Convención de las Naciones Unidas sobre el Derecho del Mar de 1982, en tanto ello no sería más que la consecuencia lógica de ser uno de los Estados pioneros en la formación del moderno derecho del mar recogido en la Convención, el Perú no se ha comprometido ante la Corte a volverse parte de la referida Convención. Tampoco ha asumido obligaciones en virtud de la Convención del Mar fuera del marco del derecho internacional consuetudinario ya existente. No debe olvidarse que tales declaraciones no pueden ser interpretadas de manera expansiva sino restrictiva. La decisión de aprobar la Convención del Mar se deberá tomar en algún momento bajo los canales que establece la Constitución Política del Perú y esperemos que la aprobación pueda producirse en un futuro no muy lejano.

\section{EL ENCARGO A LAS PARTES PARA QUE DETERMINEN LAS COORDENADAS DEL LÍMITE MARÍTIMO \\ El párrafo 197 del fallo establece que:}

En vista de las circunstancias del presente caso, la Corte ha definido el curso del límite marítimo entre las Partes sin determinar las coordenadas geográficas exactas. Más aún, a la Corte no se le ha pedido que lo haga en las conclusiones finales de las Partes. La Corte espera que las Partes determinen estas coordenadas de acuerdo con la presente Sentencia en un espíritu de buena vecindad.

Luego del fallo, las partes acordaron de manera ejemplar y en corto tiempo cuáles son las coordenadas del límite marítimo, al punto de haber sido felicitadas por el presidente de la Corte ${ }^{129}$. Sin embargo, el párrafo 197 merece un breve comentario por lo que afirma respecto a las conclusiones finales de las partes.

Si uno analiza las conclusiones finales del caso de delimitación marítima inmediatamente anterior al caso entre el Perú y Chile, es decir, del caso de la «Controversia terrestre y marítima (Nicaragua c. Colombia)», se puede verificar que en ese otro caso las partes no tuvieron que solicitar expresamente en sus conclusiones finales a la Corte que fije las coordenadas del límite marítimo ${ }^{130}$. En ese caso, fue suficiente que las

129 Ante la Comisión de Derecho Internacional de la ONU, el 22 de julio de 2014, el presidente Peter Tomka declaró lo siguiente: «Deseo felicitar a ambas Partes, y a sus líderes, por haber a los dos meses de la emisión de la sentencia acordado las coordenadas geográficas precisas de su límite marítimo sobre la base de la descripción en la Sentencia de la Corte» («Discurso de S.E. Peter Tomka, Presidente de la Corte Internacional de Justicia, en la Sexagésima Sexta Sesión de la Comisión de Derecho Internacional», 22 de julio de 2014, p. 5).

130 «Controversia territorial y marítima (Nicaragua c. Colombia)». I.C.J. Reports, 2012, pp. 636-637, párrafo 17. 
partes sugieran durante su argumentación escrita y oral cuáles debían ser las coordenadas, sin que la Corte observe ello o no fije las coordenadas. El Perú también sugirió cuáles debían ser las coordenadas del límite marítimo que propuso a la Corte que fije, lo hizo en su Memoria y en su Réplica ${ }^{131}$. Igualmente, durante las audiencias orales, el 3 de diciembre de 2012, Rodman Bundy, abogado del Perú, insistió sobre ello ${ }^{132}$.

El Perú, entonces, actuó como se pudo haber esperado de él según la práctica de las partes en el caso de delimitación marítima inmediatamente anterior. Es de notar que, en la adopción de la decisión final de la Corte en el caso Nicaragua c. Colombia, participaron casi todos los mismos jueces regulares que en el caso entre el Perú y Chile (sin contar los jueces ad hoc). En efecto, de los 14 miembros regulares de la Corte que elaboraron la sentencia en el caso Perú c. Chile, 12 también decidieron el caso Nicaragua c. Colombia: solo los jueces Bhandari y Gaja no participaron en la decisión en ese otro caso ${ }^{133}$. Se trataba, entonces, fundamentalmente de los mismos jueces y de la misma conformación de la Corte.

En el caso «Jan Mayen», la Corte indicó que calculó las coordenadas del límite marítimo «sobre la base de la información proporcionada por cada Parte a la Corte respecto a los puntos de base en las costas de su territorio» ${ }^{134}$. Tanto el Perú como Chile han notificado sus líneas de base a la Organización de las Naciones Unidas y esa información fue presentada, además, a la Corte ${ }^{135}$. En resumen, la Corte pudo fijar las coordenadas, pero optó por no hacerlo. En todo caso, las partes lo han hecho ya en cumplimiento del fallo de manera ejemplar.

\section{CONCLUSIÓN: ¿UN FALLO «SALOMÓNICO»?}

Para determinar si existía o no un límite marítimo, la Corte primero evaluó las Proclamaciones de 1947. Determinó que fueron provisionales, en base a argumentos legales, y las consideró irrelevantes para el establecimiento de un límite marítimo. Luego, analizó la Declaración de Santiago de 1952. Decidió, en aplicación de las reglas

$131 \mathrm{MP}$, párrafo 6.50 y gráfico 6.6; RP, párrafo 5.12 y gráfico R-5.1.

132 CR 2012/27, p. 40.

133 Gaja decidió no participar porque, antes de su elección como miembro regular de la Corte, fue juez ad hoc de Nicaragua en el mismo caso. Ver «Controversia territorial y marítima (Nicaragua c. Colombia)». I.C.J. Reports, 2012, p. 631, párrafo 2. Bhandari fue electo miembro regular de la Corte el 27 de abril de 2012, pero según el artículo 20 del Estatuto «[a]ntes de asumir las obligaciones del cargo, cada miembro de la Corte declarará solemnemente, en sesión pública, que ejercerá sus atribuciones con toda imparcialidad y conciencia". Esa declaración la hizo recién el 19 de junio de 2012, cuando la Corte ya se encontraba deliberando sobre el caso Nicaragua c. Colombia, lo cual explica que no participara en la toma de esa decisión. Ver «Juramentación del Sr. Bhandari, nuevo Miembro de la Corte». Nota de prensa 2012/20 del 30 de mayo de 2012 (http://www.icj-cij.org/ docket/files/103/17034.pdf).

134 «Delimitación marítima en el área entre Groenlandia y Jan Mayen (Dinamarca c. Noruega)». I.C.J. Reports, 1993, p. 81, párrafo 93.

$135 \mathrm{MP}$, párrafo 2.13 y anexo 23; DC, párrafo 2.150, anexos 70 y 132.

ANÁLISIS DE LOS PRINCIPALES

ELEMENTOS DE

LA SENTENCIA

DE LA CORTE

INTERNACIONAL

DE JUSTICIA EN

EL CASO DE LA

CONTROVERSIA

MARÍTIMA (PERÚ C.

CHILE) A LA LUZ DE

LAS POSICIONES

DE LAS PARTES

ANALYSIS OF

THE MAIN

ELEMENTS OF THE

INTERNATIONAL

COURT OF JUSTICE

JUDGMENT IN THE

MARITIME DISPUTE

(PERU V. CHILE) IN

THE LIGHT OF THE

PARTIES POSITIONS 
sobre interpretación de tratados, que ella no estableció ningún límite marítimo. Después, se enfocó en el Convenio de 1954. Sobre la base de su propia jurisprudencia, determinó que en ese tratado se reconoció un acuerdo tácito, que a su vez estableció un límite marítimo. Los jueces de la Corte se mostraron convencidos, en sus opiniones y declaraciones que acompañan la sentencia, de que esa figura legal existe.

En tanto las Proclamaciones de 1947 y la Declaración de Santiago de 1952 no eran relevantes y el Convenio de 1954 solo se aplicó a partir de la milla marina 12 de la costa, todo ello decidido en base a argumentos legales, la Corte tenía ella misma que determinar hasta dónde se extendió el límite marítimo acordado tácitamente. Nunca había realizado una labor similar. Por otro lado, las partes no argumentaron que haya existido un acuerdo tácito y no presentaron evidencia de hasta dónde se extendió ese tipo de acuerdo. No hay que olvidar que es el Estado que argumenta un hecho el que debe demostrarlo. La propia forma en la que resolvió la Corte el caso la llevó a una situación peculiar: el límite marítimo acordado tácitamente se debía extender más allá de las primeras doce, pero no hasta las doscientas millas marinas. Pero, iqué emplear para determinar la extensión de un acuerdo tácito sobre el que por su propia naturaleza no existe registro?

En el párrafo 151 del fallo, la CIJ afirma que el «material ante la Corte [...] no le proporciona información precisa sobre la extensión exacta del límite marítimo que existía entre las Partes», añadiendo que «se podría esperar que este tema debió ser resuelto por las Partes en el contexto de su acuerdo tácito y reflejado en el tratado que reconoce el acuerdo tácito, es decir el Convenio sobre Zona Especial Fronteriza Marítima de 1954. Ello no ocurrió». La Corte confirma que no tiene mayores elementos a la mano y su posición no es sencilla, pero no se advierte en esa afirmación ninguna intención de resolver la extensión del acuerdo tácito simplemente para contentar a las partes al margen del Derecho Internacional ni existe evidencia alguna de que la Corte haya intentado eso. El derecho, tal como fue aplicado por la Corte, la llevó a un punto en el que no era sencillo resolver. Pero debía resolver. Y resolvió.

La jueza Donoghue, en su declaración, afirma que «[y]o voté a favor de esta Sentencia en todos sus aspectos porque considero que refleja un resultado sensato a la luz del derecho aplicable y de la evidencia ante la Corte» ${ }^{136}$. La Corte pudo haber resuelto de manera distinta diversos puntos de su sentencia, sin duda, pero nada indica que intentaron hacer algo distinto a aplicar el derecho en el contexto de las circunstancias especiales del caso. 
Más allá del área que abarca el límite marítimo acordado tácitamente, la Corte delimitó siguiendo las bien establecidas normas sobre delimitación marítima. La Corte también decidió sobre el punto de inicio del límite marítimo sobre la base de argumentos legales, a pesar de que la decisión pudo haber sido distinta. Sin embargo, la Corte se cuidó de dejar en claro que el punto de inicio del límite marítimo no tiene por qué coincidir con el punto de inicio del límite terrestre. Por otro lado, la Corte optó por no pronunciarse expresamente sobre el segundo pedido del Perú, pero en el entendido de que no era necesario por la forma como había delimitado, es decir, de tal manera que se evidenció de inmediato que el antes llamado «triángulo exterior» corresponde enteramente al Perú.

Recibido: Aprobado:

ANÁLISIS DE LOS PRINCIPALES

ELEMENTOS DE

LA SENTENCIA

DE LA CORTE

INTERNACIONAL

DE JUSTICIA EN

EL CASO DE LA

CONTROVERSIA

MARÍTIMA (PERÚ C.

CHILE) A LA LUZ DE

LAS POSICIONES

DE LAS PARTES

ANALYSIS OF

THE MAIN

ELEMENTS OF THE

INTERNATIONAL

COURT OF JUSTICE

JUDGMENT IN THE

MARITIME DISPUTE

(PERU V. CHILE) IN

THE LIGHT OF THE

PARTIES POSITIONS 